\title{
Esbozos de retratos en las cartas de Francisco de Quevedo ${ }^{1}$
}

\author{
Isabel Pérez Cuenca \\ Universidad San Pablo-CEU \\ Dpto. de Humanidades \\ Fac. de Humanidades y CC. de la Comunicación \\ Paseo de Juan XXIII, 8 \\ 28040 Madrid \\ cuenca.fhm@ceu.es
}

[La Perinola, (Issn: 1138-6363), 22, 2018, pp. 201-246]

DOI: $10.15581 / 017.22 .201-246$

La colección de cartas escritas por Francisco de Quevedo a lo largo de su vida ofrece lecturas que permiten un conocimiento del autor desde perspectivas diferentes. Principalmente se ha recurrido a ella para documentar hitos de su biografía y de su obra, en ocasiones ha sido analizada por lo que muchas cartas tienen de avisos o relaciones de sucesos. Excepcionalmente, desde temprano, alguna carta ha sido impresa junto a otras obras de Quevedo, incluso Tarsia decidió ilustrar la vida del escritor con la publicación de una epístola dirigida a Antonio de Mendoza que, como afirma Nider, brinda a los lectores «una suerte de testamento espiritual de Quevedo»².

La lectura atenta del conjunto de cartas conservado puede abrir caminos poco transitados hasta ahora, siendo uno de ellos el que nos proponemos tomar en las páginas que siguen: coleccionar algunas descripciones de individuos, incluyendo entre ellas un par de las esbozadas de sí mismo. Quevedo domina el arte del retrato, entendido este como “la representación de un individuo con su propio carácter» ${ }^{3}$, y lo aplica a una parte importante de su obra, ya sea en prosa o en verso, satírica o no. Los retratos que hallamos en la colección de cartas conservada

1. Este trabajo se ha realizado en el marco de los proyectos FFI2015-65779-P y HAR2015-68946-C3-1-P, financiados por el Ministerio de Economía y Competitividad del Gobierno de España y el Fondo Europeo de Desarrollo Regional (FEDER) desde el 01/01/2016 hasta el 31/12/2019.

2. Nider, 2013, 12. Entre otros destacamos los trabajos y ediciones de Lida, 1980; Ettinghausen, 1994, 2006, 2011; Sánchez Sánchez, 1993, 1994; Tarsia, Vida, pp. 163-181; Quevedo, Prosa festiva; Quevedo, Nuevas cartas; Quevedo, Cartas a Sancho de Sandoval; Arranz Lago, 2009 y Pérez Cuenca, 2016.

3. Pope-Hennessy, 1985 , p. 8. 
se adaptan al contexto epistolar en el que se insertan y, por tanto, al corresponsal, aspectos ambos que han de ser valorados.

La comunicación por medio de cartas facilitaba una mayor proximidad entre los corresponsales, puesto que permitía el «secreto y deferencia» que requería la transmisión de informaciones. Por esta razón, señala Martínez Hernández, las cartas

fueron un instrumento esencial e indispensable en las alianzas y vínculos establecidos entre los miembros de la corte sirviendo de privilegiado «canal para el vital envío de informaciones y para el mismo ejercicio de solidaridad entre sus miembros» e incluso también, en muchos casos, el origen de las redes o bandos cortesanos ${ }^{4}$.

Las cartas de Quevedo no son una excepción en este sentido, la correspondencia con Francisco de Oviedo, con el duque de Medinaceli, con Sancho de Sandoval, con el conde de la Roca y con otros más son ejemplo de vínculos, alianzas y distanciamientos entre los miembros de la corte. Esta circunstancia también se ha de tener en cuenta a la hora de estudiar algunos de los retratos o figuras que en ellas se deslizan.

Sobre la variedad de documentos coleccionados con el título de Epistolario ${ }^{5}$, hemos seleccionado un grupo de cartas que, en un principio, han de considerarse privadas y no ficticias; es decir, las cartas objeto de este trabajo no son inicialmente resultado de prácticas epistolares literarias; aunque como se verá pueden llegar a serlo parcialmente o incluso considerarse plenamente como tales. Así pues, de los muchos documentos publicados en el Epistolario solo atenderemos a aquellas cartas que estrictamente son práctica de la comunicación social y van dirigidas a un destinatario real, aunque estas hayan sido objeto de lectura pública ${ }^{6}$.

Tras una revisión de todas las cartas de Quevedo, se han seleccionado, por un lado, tres autorretratos y, por otro, descripciones de personas reales. En primer lugar comparamos los autorretratos de dos cartas que por su carácter jocoso, sus destinarios nobles y su difusión han corrido suertes parejas: la carta sobre el viaje a Andalucía del rey Felipe IV

4. Martínez Hernández, 2004b, pp. 472-473.

5. Las colecciones con mayor número de cartas publicadas hasta ahora son las editadas por Astrana Marín, Quevedo, Epistolario, y por Sliwa, Quevedo, Cartas, documentos y escrituras. Sobre la heterogeneidad de los documentos recogidos en la edición de Astrana, véase Sánchez Sánchez, 1993.

6. Véanse los trabajos de Guillén, 1986, 1991 y 1998, donde trata de la literariedad -opción con la que el escritor y el lector se comprometen desde un principio- frente a la poeticidad -valor producido por la escritura y la lectura, a través de la intervención de una imaginación simbólico-imaginativa-, conceptos tomados de García Berrio; a su vez establece la diferencia entre cartas privadas y literarias, la cual estriba en la medida que el autor aplica su creatividad, y también trata de la ficcionalidad, signo de identidad importante de la literariedad. Sobre la ficcionalidad, recuerda Claudio Guillén, que existen grados y medidas y que ya está presente en los manuales epistolares del siglo xvi y en alguno de los modelos de cartas que en ellos aparecen. Sobre la naturaleza de lo epistolar véanse también los trabajos de Beltrán Almería, 1996 y 2009. 
(1624) escrita para el marqués de Velada y la Carta de las calidades de un casamiento (1633) enviada a la condesa de Olivares. A estas le sigue otra, redactada en 1643, elegida por el contraste establecido entre pasado y presente, lo que hace pensar en un implícito proceso de cambio o transformación en el individuo descrito, es decir, en Quevedo.

En un segundo apartado, se analizarán las descripciones de una portuguesa (criada del duque de Medinaceli) y de un sujeto apodado el «Embustero», individuos ambos sin relevancia en el entramado cortesano o en el de las relaciones personales de Quevedo y sus destinatarios, a los que hemos sumado la descripción de don Gaspar de Bonifaz, caballerizo del rey Felipe IV en el año 1624, y Miguel de Cárdenas, ambas insertas en la misiva ya mencionada dirigida a Velada. En todas tres, las descripciones pergeñadas transforman a personas de carne y hueso en esbozos de (figuras», desempeñando un papel importante la representación escénica en su elaboración.

Finalmente en un tercer apartado se han seleccionado retratos breves, por un lado, en unos el contexto espacio temporal está en función del elogio o del vituperio del sujeto. Por otro, un grupo en el que el nombre del sujeto descrito se oculta y cuya identidad es desvelada por el destinatario gracias al retrato. Por último, veremos un grupo de retratos realizados con brevísimas descripciones basadas en neologismos construidos a través de la aposición, pues estos sumados a otras construidas con perífrasis descriptivas, con la desautomatización de unidades fraseológicas y sobre todo paralelismos y antítesis formadas por sucintas frases yuxtapuestas. Estas constituyen las formas de descripción de individuos más repetidas en la correspondencia de Quevedo?

Hemos de puntualizar que empleamos el término «retrato» en el amplio sentido de descripción o representación de un individuo del que, según las apreciaciones de la retórica, se analizan o descubren aspectos externos (prosopografía) o internos (etopeya) y, desde el plano de la inventio, más concretamente desde los argumenta o loci a persona, se estudia al ser humano de acuerdo a sus distintos componentes o características, no todos ellos inherentes a su naturaleza ${ }^{8}$. El término "figura» lo utilizamos con el sentido apuntado por Eugenio Asensio: «Figura, hacia 1600, pasa a significar sujeto ridículo o estrafalario, cargándose la palabra de un énfasis peyorativo que sugiere afectación ridícula» ${ }^{9}$.

7. Lía Schwartz ya observó en 1974 (recuperado en 1986, citamos por aquí), en un estudio acerca del retrato literario satírico en la obra de Quevedo, cómo las descripciones de tipos y figuras, tanto de su prosa como de su poesía, permiten señalar los modelos clásicos de Teofrasto y del retrato retórico tradicional frente a la creación original de Quevedo que se manifiesta en los retratos breves, donde «la concentración de la expresión en frases breves, yuxtapuestas en relación de paralelismo o de antítesis es un rasgo fundamental del estilo de Quevedo» (p. 254).

8. Sobre el retrato literario véase Iriarte López, 2004, pp. 127 y 162.

9. Asensio, 1971, p. 80; véanse también las pp. 77-86 y 189, Romanos, 1982; sobre las «figuras» en la Hora de todos, López Grigera, 1988, pp. 31-36, y en la poesía satírico burlesca, Arellano, 2003, pp. 98-103. Cercanas a la definición de Asensio son las registradas en 
Aprovechamos para recordar, como ya hizo Asensio, que fue Quevedo quien crea la primera teoría sobre la figura y describe sus primeras muestras en Vida de la corte, aunque con la palabra figura se recorre un nutrido conjunto de significados a lo largo de toda su obra.

\section{Autorretratos}

De las cartas seleccionadas solo dos pueden pasar por jocosas, son las escritas al marqués de Velada y a la condesa de Olivares ${ }^{10}$. Comparten ambas varios aspectos: las dos fueron pronto impresas con las obras satíricas, políticas y devotas del autor (Madrid: Diego Díaz de la Carrera: a costa de Tomás Alfay, 1650) ${ }^{11}$; el contenido es humorístico, lo cual les acerca a sus obras burlescas, y todo hace pensar que fueron escritas “más por divertir que por informar»" Muy probablemente Quevedo tuvo presente, en el momento de su redacción, que los destinatarios compartirían la carta con otras personas, ya que, de acuerdo con Gómez Moreno, las «cartas jocosas» como estas conllevan el placer de escribir del autor a la vez que el de la lectura del destinatario, que «se sospecha o se desea múltiple» ${ }^{13}$.

Covarrubias: «Cuando encontramos con algún hombre de humor y extravagante, decimos dél que es linda figura», y Autoridades: «Se llama jocosamente al hombre entonado, que afecta gravedad en sus acciones y palabras», esta acepción se autoriza con un pasaje de la Premática del tiempo de Quevedo; también en Aut: «Por extensión se toma por hombre ridículo, feo y de mala traza».

10. Las cartas al marqués de Velada y a la condesa de Olivares se citan por la edición de García-Valdés, en Quevedo, Prosa festiva, pp. 379-388 y 460-467.

11. Ambas, como nos recuerda García Valdés, 1993, p. 117, se añadieron al volumen después del colofón.

12. Quevedo incide sobre este objetivo en la carta a la condesa de Olivares (Quevedo, Prosa festiva, p. 461) y Sancho de Sandoval se lo recuerda en el comento que realiza de la Carta de las calidades de un casamiento que le remite: «v.M. escribió más por divertir que informar a mi Sra. la condesa” (вNE, ms. 20274 / 3, fols. 2r y 11v). Fernando del Pulgar, en el siglo xv, defendió en una de sus letras la incorporación de materia jocosa en las cartas. Con Erasmo y luego con Vives el estilo jocoso se reafirma sin vacilación en el género epistolar y la «jocosa» va a ser considerada una modalidad más de carta, como sucede con Juan Páez de Valenzuela y Castillejo, quien incluye la carta jocosa entre los ocho tipos que detalla en Para secretarios de señores y todo género, p. 202.

13. Gómez Moreno, 1994, p. 182. Que la carta a Velada se leyó en público o se compartió con otros queda probado cuando el marqués, en la carta de respuesta, hace referencia a un fragmento de la carta de Quevedo que ha sido objeto de comentarios en la corte: «Lo de “¿Quién descalza allá abajo?” ha parecido bonicamente en esta corte; si bien a un contemplativo le pareció que cuando vuesa merced lo decía, respondían debajo: “¿Quién le puede descalzar, que le vengan sus zapatos?" Aquí le fui amigo, y dije "que D. Francisco de Guzmán”, que es de la orden de sus patas» (Quevedo, Epistolario, p. 120). Sancho de Sandoval conocía el contenido de la carta, de la que cita literalmente un breve fragmento en la Respuesta [... . a la carta que D. Francisco de Quevedo escribió a la condesa de Olivares, sobre si es mejor tener mujer fea que hermosa (BNE, ms. 20274 / 3, fols. 2v y 12v). Por esta respuesta también sabemos que Sandoval llegó a hacerse con una copia manuscrita de la carta a la condesa de Olivares. Sobre la difusión de estas dos cartas y otras más véase Sánchez Sánchez, 1993, pp. 299-301. 
Pero nos interesa destacar las diferencias existentes entre ambas, que derivan del corresponsal y de la relación que el autor, Quevedo, establece con ellos, lo que también se deja ver en los retratos. Pues, a pesar de los muchos formularios, manuales o tratados epistolares que establecían las pautas para la redacción de cartas, la práctica epistolar gozó de una amplia libertad solo limitada por el decoro -es decir, por el destinatario y la relación del escritor con él-, convirtiéndose este, desde Petrarca, en uno de los pilares del género epistolar, no olvidado en De conscribendis epistolis de Erasmo ni en los manuales que le siguieron ${ }^{14}$.

La primera, la carta escrita a Velada ${ }^{15}$, se acoge a la estructura tripartita formada por apertura (saludo), desarrollo (información o contenido) y cierre (despedida y data), la que tienden a enseñar los manuales epistolares del Siglo de Oro ${ }^{16}$. Pero la carta en cuestión carece de inscriptio o saludo formulario correspondiente a la dignidad del destinatario y en la subscriptio, formada por la fórmula de despedida y fecha, Quevedo no menciona al marqués, a quien escribe, y omite la data ${ }^{17}$. El cierre se limita a una habitual fórmula de cortesía dirigida a dos personas identificadas solo por sus nombres: «A don Andrés beso las manos y a don García. A firmar, que es larga carta» ${ }^{18}$.

Respecto al desarrollo, los tratados aconsejan que los temas se expongan según su relevancia; una vez comunicados los asuntos importantes, se debe de responder a las cuestiones planteadas en carta precedente $y$, por último, abordar los temas que surjan al hilo de los ya tratados. Sin embargo, la carta al marqués de Velada no se ajusta a esa organización de la información. Recordemos que la carta es conocida por un título que alude al viaje que hizo Felipe IV a Andalucía en el mes de febrero de 1624, el cual promete una carta-relación del mencionado viaje del monarca ${ }^{19}$. Quevedo opta por seguir en su relato el orden del

14. Martín Baños, 2005, p. 343.

15. Sobre esta carta pueden leerse los trabajos de Madroñal, 2004; Martínez Bogo, 2009, pp. 345-348 y Plata, 2016.

16. Castillo Gómez, 2002, p. 90.

17. Los dos manuscritos empleados por García-Valdés están incompletos al final, por tanto, el cierre de la carta está tomado del impreso de 1650. Véase Quevedo, Prosa festiva, p. 386, n. 74. No se ha de olvidar que, de las cartas aquí estudiadas, solo son autógrafas las escritas a Sancho de Sandoval, el resto nos ha llegado en copias manuscritas de los siglos XVII y XVIII.

18. Quevedo, Obras festivas, p. 388.

19. García-Valdés informa de dos manuscritos: 1) ms. 109 de la Biblioteca Menéndez Pelayo (siglo XVII), título: Carta de don Francisco de Quevedo escrita al marqués de Velada en la jornada que hizo el rey a Sevilla [...] en febrero de 1624; 2) ms. 9 / 411 de la Real Academia de la Historia (segunda mitad siglo XVII), título: Carta que don Francisco de Quevedo [...] escribió a un grande de España, dándole cuenta del viaje que hizo el rey de España dende [sic] Madrid a Sevilla, por el mes de febrero de 1624 años. En el impreso: Carta del viaje del rey nuestro señor a Andalucía. García-Valdés cree posible que Alfay tuviera a la vista materiales proporcionados por Quevedo (Quevedo, Prosa festiva, p. 94, n. 153). Madroñal, 2004, p. 239, da noticia de otras dos copias del siglo XVII, para su localización solo aporta la información siguiente: localizadas en el fondo Rodríguez-Moñino de la Real Academia Española: «una la que hacia 1660 copia en su cartapacio Diego Ignacio de Góngora (ms. 
itinerario del viaje $\mathrm{e}^{20}$, sin dar prioridad, al no situarla al inicio de la carta, a la información sobre Felipe IV. La misiva comienza -por consiguiente resalta- un suceso en el que el escritor está involucrado; se trata de un percance sufrido, antes de llegar a Aranjuez, con el coche en el que viaja. Pero este es solo el inicio, pues se puede afirmar que presta más atención a su persona y a otros miembros de la comitiva que al rey. Las localidades visitadas y las personas mencionadas son las siguientes:

1) Camino de Aranjuez: Quevedo, almirante de Castilla y cochero.

2) Aranjuez: Quevedo y almirante de Castilla.

3) Tembleque: Felipe IV y Bonifaz.

4) Madrilejos y Membrilla: Bonifaz.

5) Torre de Juan Abad: «Caballero de la Tenaza» y Miguel de Cárdenas.

6) Santiesteban: Conde de Santiesteban.

7) Cercanías de Linares: Quevedo, Gaspar de Tebes, Mateo Montero.

8) Linares: Quevedo, Bonifaz, Francisco de Marbelle [Morovelli?], Juan de Arana, Mendoza, Felipe IV, «Zapatilla», «Zapatón», Montero.

9) Andújar: Duque del Infantado, Patriarca, Felipe IV, Bonifaz, señor Araciel y Hortensio.

Quevedo fija su atención en personas de la comitiva, también hace referencia a sí mismo, mientras que el rey -mencionado en tres ocasiones- pasa a un segundo término y, sorprendentemente, nunca nombra al conde de Olivares ${ }^{21}$. Las pocas o nulas noticias sobre las dos personas más relevantes de ese viaje podrían decepcionar a los nobles y cortesanos que quedaron en Madrid; sin embargo, todo apunta a que la carta de Quevedo gozó de una gran aceptación entre el público lector cortesano $^{22}$. Quevedo además no inicia la narración con la inscriptio pre-

6877), basándose en una copia anterior; otra, la recogida en el volumen de manuscritos de Solórzano y Pereira, que también agrupa otros textos de Quevedo».

20. Plata, 2016, p. 161, describe esta carta jocosa como "una especie de "cuaderno de bitácora" en clave burlesca, quizá parodia de las muchas relaciones que circularon en la época».

21. Olivares tuvo que tener gran protagonismo en este viaje, pues fue su artífice. Señala Ezquerra Revilla, 2011, p. 41: «Esta jornada fue concebida por el flamante valido, Gaspar de Guzmán, a modo de demostración pública de su instalación en la gracia real, como señala el hecho de que cada entrada en las ciudades más importantes del recorrido contaba con su presencia en el estribo del coche real, en su señera calidad de caballerizo mayor, a la que sumaba la de sumiller de corps». Se considera que el motivo del viaje fue para proteger las costas andaluzas de un posible ataque inglés, pero también se apuntan otros como obtener nuevos impuestos de Andalucía, recuperar el poderío naval y comercial y afianzar Olivares su poder (Plata, 2016, p. 161).

22. La respuesta del marqués alude a la difusión del contenido de la carta en dos ocasiones: “Lo de “¿Quién descalza allá abajo?” ha parecido bonicamente en esta corte. [...] Andrés, aquel anochecido de rostro, tan Mendoza por línea curva como mulato por línea recta, ha enviado aquí quejas de que vuesa merced escribe las nuevas sin su licencia» (Quevedo, Epistolario, pp. 120, 121). 
ceptiva, sino que opta por un inicio in media res centrado en su persona y completamente alejado de cualquier preámbulo relacionado con los preparativos del viaje, de cómo fue la salida de la corte, y sobre todo, como decimos, sin noticias acerca de las dos personas que fueron el centro de todas las miradas: el monarca y su valido. Deliberadamente obvia todo ello y comienza el relato con el pronombre personal «yo» y una figura etimológica (caí, cayó, caída) que le permite aludir a sus pies, los cuales por sí solos son condicionante suficiente para causar un tropiezo que le hiciese caer — (Mis pies no han menester [apetites] para tropezar». Es esta alusión a un reconocido defecto físico del escritor lo que facilita la inserción de una escueta prosopografía, construida con una oración atributiva compuesta de dos elementos simétricos y cuasi sinónimos en coordinación: “tartamudo de zancas» junto a (achacoso de portante» $)^{23}$ :

Yo caí, san Pablo cayó; mayor fue la caída de Luzbel. Mis pies no han menester [apetites] para tropezar: soy tartamudo de zancas y achacoso de portante. Volcose el coche del almirante (íbamos seis en él) ${ }^{24}$; descalabrose don Enrique Enríquez; yo salí por el zaquizamí del coche, asiéndome uno de las quijadas; otro me decía: «Don Francisco, dame la mano». Yo decía: «Don Fulano, dame el pie». Salí de juicio y del coche. Hallé el chochero hecho santiguador de caminos, diciendo: «No me ha sucedido tal en mi vida». Yo le dije: «Vuesa merced le ha volcado de manera que parece lo ha hecho muchas veces» ${ }^{25}$. Llegué a Aranjuez y aquella noche dormimos don Enrique y yo en dos obleas y sin almohadas. Pero todos los duelos con el almirante son buenos ${ }^{26}$.

El inicio del relato en primera persona -con el pronombre personal “yo» y con la figura etimológica-; la burlesca descripción de sí mismo, basada exclusivamente en su cojera y ridiculizada gracias al uso y combinación de los términos tartamudo, achacoso, zancas y portante ${ }^{27}$; la

23. Quevedo repite esta caracterización física en la carta a la condesa de Olivares como veremos más adelante. También hace alusión a piernas y pies en dos autorretratos más detallados de dos obras festivas, igualmente en estructuras bimembres: Memorial que dio a una academia pidiendo plaza en ella («quebrado de color y de piernas [...], falto de pies y de juicio») y Carta a la rectora del Colegio de las Vírgenes ("falto de pies y de dicha [...], largo de zancas y de razones» (Quevedo, Obras completas, vol. 2, t. 1, pp. 174 y 287).

24. Sandoval, en la Respuesta, fols. $2 \mathrm{v}$ y 13, afirma que el coche en el que viajaron era de Juan de Arana: «Se confesó achacoso de portante pintando la estrechura del coche de Juan de Arana, en que iban nueve con dale Perico».

25. Santiguador: «Persona que cura con ensalmos, haciendo cruces y otras ceremonias» (Aut); el cochero es santiguador de caminos porque gesticula y maldice. Obsérvese que completa la descripción con el diálogo.

26. Quevedo, Prosa festiva, p. 379. Este pasaje es comentado por Martínez Bogo, 2009, p. 345, véanse también las pp. 346-348.

27. El término «tartamudo»-exclusivo para expresar una dificultad del habla («torpe o tardo en la pronunciación por algún impedimento de la lengua» (Aut) - es aplicado a las piernas, llamadas aquí zancas y así juega con el sentido recto de la palabra -pata de las aves- y con el figurado - (pierna larga y delgada del hombre» (Aut)-. Juego similar establece con (achacoso de portante», donde (achacoso» - enfermo o con achaques o vi- 
perífrasis descriptiva del cochero, junto al estilo directo que introduce en dos ocasiones, una con un tal "don Fulano» y otra con el cochero, convierten la información acerca de un accidente en un relato hilarante con el que se consigue fijar la atención del lector en su persona, protagonista de este y otros pasajes de la carta en los que reprueba la falta de comodidades y las condiciones adversas en las que se desarrolla el viaje.

A partir de aquí, el itinerario del viaje se sigue, en su mayor parte, a través de una narración en primera persona del plural, de forma excepcional se recurre a la tercera o primera personas del singular ${ }^{28}$. En todo caso, la carta relata principalmente los sucesos que le acontecen a él y a los que le acompañan durante esas jornadas primeras hasta llegar a Andújar.

Habría que preguntarse si tras esto no se oculta una crítica a un viaje que supuso un dispendio económico, emprendido en una época poco recomendada por razones climatológicas, planificado por Olivares como prueba de su poder, sin importarle arrastrar al rey y a media corte por caminos intransitables y sin disponer del debido alojamiento para toda la comitiva ${ }^{29}$. Rafael Ortega y Sagrista ya apuntó las dificultades que hubo para alojar a la numerosa comitiva real, así como lo inapropiado de la fecha para viajar:

El viaje se inició en una estación adversa a los desplazamientos, con bajas temperaturas y frecuentes precipitaciones, por caminos malos y embarrados, donde los coches y caballerías se atascaban. Así, pues, el viaje resultó largo y lento.

Salió Felipe IV de Madrid el 8 de febrero, «aunque con riguroso tiempo» y no volvió hasta el 19 de abril. Más de dos meses durante los cuales terminó aquél duro invierno, al que siguió una primavera revuelta y desapacible ${ }^{30}$.

cios o defectos- entra en contradicción con el significado de «portante»-marcha o paso apresurado, aplicado regularmente a las caballerías (Aut)-. Quevedo en Visita de los chistes (p. 545 y n. 99) construye un juego de palabras similar: «Lenguas de portante». Quevedo utiliza, para referirse a sus piernas y pies, las palabras «zancas» y "portante» propias del campo semántico del reino animal (aves o cuadrúpedos), lo que contribuye a la deformación o caricaturización de sí mismo. Léase Schwartz, 1984, pp. 160-163, en p. 162 se cita este pasaje.

28. Primera persona del plural: «Fuimos a Madrigalejo (sic)», «salimos para la Membrilla», "venimos a la Membrilla», "partimos para mi Torre de Juan Abad», "fuimos a Santisteban», (pasamos a Linares», (íbamos en un coche», «nos determinamos dormir allí», «estuvimos hablando», «llegamos a Linares», (cenamos», «dormimos a pares», «llegamos tarde a Andújar». Tercera persona singular, pero habla de sí mismo: «El Caballero de la Tenaza se recató de todos», es decir, receló de todos. Recuérdese que el Caballero de la Tenaza buscaba prevenir a «todo caballero para salvar su dinero a la hora de la daca». Primera persona del singular: «Yo vengo sin pesadumbre y sin cama».

29. El doctor Juan de Quiñones fue el encargado de la preparación de los caminos, el licenciado Miguel de Cárdenas y Chincoya - a quien alude Quevedo en la carta y del que trataremos más adelante- fue especialmente comisionado para la aportación de abastos, y estos junto al licenciado Garci Pérez de Araciel, oidor del Consejo Real y camarista también Quevedo hace referencia a él-, eran los «integrantes de un aparejo de gestión móvil de la gracia y la justicia, entre los cortesanos desplazados y en aquellos lugares por los que discurría el viaje real» (Ezquerra, 2011, p. 41).

30. Ortega y Sagrista, 1978 , p. 56 y pp. $58-59$. 
La carta en su conjunto, refleja una relación del escritor con el marqués de Velada basada en la cercanía y confianza, aspectos a los que responden el humor y la crítica - no exenta de cierta complicidad ${ }^{31}$-, la estructura formal de la misiva y el orden y selección de noticias que comunica $^{32}$. También ha de subrayarse la notable ausencia de información sobre Olivares, enfrentado a Velada desde su llegada al poder ${ }^{33}$, lo que no puede ser gratuito al igual que las muchas notas que introduce sobre los problemas con los que Quevedo y compañía se enfrentan a diario. El motivo de la carta, si tenemos en consideración todo esto, no parece ser el viaje que su majestad realizó a las Andalucías sino el incómodo y accidentado viaje que realizó Quevedo con la comitiva real. En este contexto, la función que la breve descripción física desempeña en esta misiva no es otra que el servir de ornamento retórico, recurso que contribuye a captar la atención del lector en una carta crítica con la jornada planificada por el valido para su propio lucimiento ${ }^{34}$.

En el año 1633, quizás el 7 de diciembre, Quevedo escribió a la condesa de Olivares, doña Inés de Zúñiga y Velasco, la Carta de las calidades

31. Cuando se dirige Quevedo con sus acompañantes a Linares, los infortunios del viaje continúan a causa de la orografía del camino, entonces escribe Quevedo a Velada: «Aperciba vuecelencia la risa, hártese de venganza, logre sus profecías». Velada debió verse obligado a quedarse en la corte y debió pronosticar las dificultades con las que se encontraría la comitiva. Al final de la carta, tras darle noticia de que Bonifaz ha tratado de sus negocios con Garci Pérez de Araciel, Quevedo escribe: «él [Bonifaz] y yo somos servidores de vuecelencia y suyo, y a su disposición, y cofrades del diente» (Quevedo, Prosa festiva, pp. 383 y 388); (diente»: en sentido moral se atribuye a la envidia o maledicencia, cuando con la lengua o la pluma destrozan y despedazan la buena opinión de otros (Aut). Ambos fragmentos ponen de manifiesto esa «cierta complicidad» a la que nos hemos referido. Creemos importante destacar que Garci Pérez de Araciel, vicecanciller del Real Consejo de Aragón, además de consejero de Castilla, del Consejo de Hacienda y las Indias, también fue caballero de la Orden de Santiago, y, al igual que la casa de los Velada, fue un hombre favorecido por el rey Felipe III, quien le nombró para esos cargos. Tuvo una protagonista intervención en los procesos contra Lerma, Rodrigo Calderón y Osuna. Murió el 29 de septiembre de 1624, tres días antes - «estando para darle la extrema unción», dice una gaceta de la época- Felipe IV le hizo de su Consejo de Estado.

32. El cuerpo de las noticias lo constituye los percances e incomodidades sufridas por Quevedo y sus acompañantes, otros miembros de la comitiva -Bonifaz de forma destacada- y la recepción preparada por el VII conde de Santisteban del Puerto, Francisco Benavides y de la Cueva.

33. De Bonifaz nos ocuparemos más adelante. Quevedo destaca el recibimiento y agasajo del VII conde de Santisteban, “ostentoso y magnífico», que queda algo deslucido por el comentario final: «faltaron camas y sobraron coches». Mercado Egea, 1973, pp. 164-165, aporta documentación de la villa de Santisteban que corrobora el pasaje de Quevedo. Para Quevedo en relación con los Benavides, véase López Ruiz, 2008, pp. 258-260; para la casa de Velada y su relación con el conde duque, léanse los trabajos de Martínez Hernández, 2004a y 2004b y sobre el triángulo Quevedo, Velada y Olivares léase Pérez Cuenca y Campa Gutiérrez, 2017, pp. 1953-1958.

34. Esta crítica también se percibe implícita en la respuesta de Velada cuando menciona la caída de Quevedo (Quevedo, Epistolario, p. 120): “Haber caído no me admira; de lo que deja de caer, me espanto»; caer: «Perder la dignidad o el estado» (Aut). 
de un casamiento ${ }^{35}$. Afirma Sancho de Sandoval de este papel, «según me han dicho, se escribió por gusto de la reina nuestra señora» ${ }^{36}$. Quevedo escribe para satisfacer el gusto real y lo hace a través de una carta que dirige a su camarera mayor, Inés de Zúñiga, por lo que era su misión estar al cuidado de Isabel de Borbón y la gobernanza de sus habitaciones $^{37}$. En ese mismo año el distanciamiento de Quevedo con el conde duque de Olivares es seguro y la proximidad al duque de Medinaceli -quizás a su servicio desde 1630- le sitúa en la facción contraria, oposición que se hace patente en Execración contra los judios, obra datada en Villanueva de los Infantes, en julio, meses después de entregar a la imprenta el tratado moral de La cuna y la sepultura. Además, desde al menos un año antes, el duque de Medinaceli está en tratos para concertar el matrimonio del escritor. Considera Hermès (2014, pp. 560-562) que en esta carta Quevedo busca «concretar una creación ficcional propicia a asentar su fama en las altas esferas, en vez de una carta puramente reflexiva e informativa $)^{38}$. Todas estas circunstancias deben ser tenidas en cuenta al leer esta carta.

Es destacable que tanto la salutatio -«Excma. Sra.»- como la fórmula final de captatio benevolentiae en la petitio-«Dé Dios a vuecelencia muchos y bienaventurados años en vida del conde duque, mi señor, con la sucesión que su casa y grandeza ha menester y deseo»- junto a la conclusio - «xxcma. Sra. Besa a V. Ex. ${ }^{a}$ la mano su criado Don Francisco de Quevedo» - son acordes a la dignidad de la destinataria y posición que esta ocupa en la corte real; además, como establecían los formularios epistolares, no olvida en el exordio ganarse la voluntad de la condesa. Estamos ante una carta en la que Quevedo se ajusta a los parámetros formales que rigen el arte epistolar, adecuando los elementos formularios al destinatario.

Por tanto, la presencia de estos elementos, frente a la carencia de ellos en la relación burlesca que hizo del viaje a Andalucía para Velada, impone una distancia considerable entre una y otra misiva, que puede ser indicio de la diferente relación que existe entre Quevedo y los nobles destinatarios, lo que se entrevé también en el desarrollo de las car-

35. Sobre la fecha, el título de la carta e impresos y manuscritos que la transmiten remitimos a Quevedo, Prosa festiva, pp. 116-117; Pérez Cuenca, 1997, y el ya citado de Sancho de Sandoval (ms. 20274 / 3); en total se conocen 18 manuscritos de esta carta.

36. вNE, ms. $20274 / 3$, fols. 2r y 11 r.

37. Desempeña este cargo desde 1627 hasta la caída del conde duque en 1643 . Muerto ya el conde duque de Olivares, Quevedo, en una carta dirigida a Francisco de Oviedo, Torre de Juan Abad, 6 de agosto de 1645, califica de locura la posibilidad de regresar la condesa de Olivares a ocupar el cargo de camarera mayor (Quevedo, Cartas nuevas, p. 185): «Lo que en palacio temen, que vuelva a ser camarera mayor la condesa, es la mayor locura que ha pasado por la cabeza de nadie, porque nunca vino menos a propósito que ahora que viene viuda».

38. Sobre las circunstancias que rodean a esta carta véase Jauralde, 1998, pp. 633637; Sánchez Sánchez, 2004; Martínez Bogo, 2009; Hermes, 2014. Para Execración contra los judíos véase Cabo Aseguinolaza y Fernández Mosquera, 1993, y Pérez Cuenca, 2016 para la relación entre Quevedo y Medinaceli. 
tas: las burlas, sátiras y críticas fluyen en la dirigida al marqués, mientras que en la Carta de las calidades de un casamiento las burlas no se plasman con total plenitud hasta alcanzar la extensa petitio, donde incorpora la descripción de su modelo ideal de esposa ${ }^{39}$.

La descripción de Quevedo en la carta de 1624, como se vio, queda reducida a la cojera, pero es importante resaltar que se desarrolla en un contexto espacio temporal concreto -en el camino de Aranjuez, el día 8 de febrero de 1624- y que forma parte de la narración de un suceso en el que Quevedo se presenta en compañía de dos individuos, el almirante de Castilla y el cochero, con quien incluso entabla un diálogo. Mientras, en la carta a la condesa, Quevedo dibuja su retrato en la parte no burlesca o donde lo burlesco se haya difuminado. La descripción adquiere mayor profundidad que en la carta de Velada, donde quedó reducida a una mera mención de un defecto físico, ya que la prosopografía y la etopeya se unen para componer un retrato de mayor complejidad.

En la primera carta, el defecto físico contribuye a completar el relato burlesco del accidente con el coche; mas en la segunda, la cojera es empleada para señalar cómo se refieren a él sus enemigos, lo que sin duda responde a la realidad: «Los que me quieren mal me llaman cojo, siendo así que lo parezco por descuido, y soy, entre cojo y reverencias, un cojo de apuesta, si es cojo o no es cojo ${ }^{40}$.

Recuérdese que un autor anónimo se valió del mote Pata-Coja para atribuirle en unas coplas en el Chitón de las tarabillas:

\author{
¿Quién al de vergüenza poca \\ le ayudó para el Chitón? \\ ¿Y quién compuso el Buscón \\ con tarabilla tan loca? \\ ¿Y quién siempre se desboca, \\ en la fucia del privado \\ a quién falsamente ha dado \\ a entender que es de la hoja? \\ Pata-Coja,
}

y para involucrarle en la conjuración de Venecia:

Y quién es aquel bergante que, heredero de alquiceles, los transformó en brocateles

39. García-Valdés (Quevedo, Prosa festiva, p. 117) señala que hay ciertas reservas para considerar esta obra festiva por ser absolutamente seria su parte inicial; Martínez Bogo, 2009, p. 348, comparte esta opinión, al menos sobre parte de la carta: «La obra no se puede considerar en su totalidad burlesca, pues comienza y termina con un tono más grave de lo habitual en este tipo de obras». Sobre la «petición de burlas» léase Hermès, 2014, pp. 557-560.

40. Quevedo, Prosa festiva, p. 462. Este pasaje es comentado por Hermès, 2014, p. 555, y por Martínez Bogo, 2009, p. 350. 
y se los dio a su informante?

¿Y quién es un ignorante

cuya estatua allá en Venecia,

por una frialdad muy necia,

calentaron con seroja?

Pata-Coja ${ }^{41}$.

Unos años después, 1635, se advierte en El tribunal de la justa venganza que es “conocido por el Diablo cojuelo y Patacoja ${ }^{42}$ a causa de la deformidad de sus pies. Finalmente, Góngora juega con tres significados del término pies para aludir también a su cojera en el cuarteto de un conocidísimo soneto, probablemente, de fecha cercana a la traducción y paráfrasis del Anacreón castellano de Quevedo (1609): "Anacreonte español no hay quien os tope, / que no diga, con mucha cortesía, / que ya que vuestros pies son de elegía, / que vuestras suavidades son de arrope» ${ }^{43}$.

El retrato va a ser resultado de una descripción que va más allá de los elementos anatómicos o morales, con el fin de dibujar un perfil amplio y completo de sí mismo. Para ello aporta, por un lado, los rasgos innatos de su persona - prosopografía y etopeya- y por otro, los que no son propios de su naturaleza externa o interna, tales como el nacimiento, la fortuna o el modo de vida (argumenta a persona). En la prosopografía elude el detalle de particularidades físicas, quedando reducida aquella a una breve observación sobre el conjunto de su figura, que se justifica no por la necesidad de describir su apariencia, sino para resaltar el efecto que su físico provoca en otros: «Mi persona no es aborrecible ni enfadosa; y ya que no solicita alabanzas, no acuerda de las maldiciones y la risa a los que me ven» ${ }^{44}$. Por tanto, toda referencia a su aspecto físico se construye desde el punto de vista de «otros», ya sean los que le «quieren mal» o ya sean «los que le ven», por lo que es una prosopografía no objetiva, reflejo de la opinión ajena.

De mayor interés es la etopeya que se orquesta a partir de argumenta como el nacimiento, naturaleza o modo de vida, junto con fortuna, hacienda y edad. El autorretrato está desprovisto de contexto espacial y temporal, por lo que traza una semblanza estática, que por sí misma incita al lector a la reflexión. La descripción completa es la siguiente:

Yo, señora, no soy otra cosa sino lo que el conde mi señor ha deshecho en mí, puesto que lo que yo me era me tenía sin crédito y acabado; y si hoy soy algo, es por lo que he dejado de ser, gracias a Dios y a su excelencia.

He sido malo por muchos caminos; y habiendo dejado de ser malo, no soy bueno, porque he dejado el mal cansado, y no arrepentido. Esto no

41. Quevedo, Obras, vol. 2, pp. 667 y 653. Fernández-Guerra fecha esta sátira en 1632. 42. Pacheco de Narváez, Tribunal, p. 77.

43. Góngora, Antología poética, p. 293, sin fecha. Léase además la anécdota que narra Tarsia, Vida, pp. 105-106, con ocasión de la visita de Quevedo a unas damas.

44. Quevedo, Prosa festiva, p. 462. 
tiene otra cosa buena sino asegurar que ningún género de travesura me engañará, porque todas me tienen, u escarmentado u advertido.

Yo soy hombre bien nacido en la provincia: frasis que entenderá su excelencia. Soy señor de mi casa en la Montaña; hijo de padres que me honran con su memoria, ya que yo los mortifico con la mía.

El caudal y los años siempre os referiré de manera que después la hacienda sea más, y la edad, menos.

Los que me quieren mal me llaman cojo, siendo así que lo parezco por descuido, y soy, entre cojo y reverencias, un cojo de apuesta, si es cojo o no es cojo.

Mi persona no es aborrecible ni enfadosa; y ya que no solicita alabanzas, no acuerda de las maldiciones y la risa a los que me ven ${ }^{45}$.

En los dos primeros párrafos, mediante la utilización de los verbos en pasado y presente y junto con el empleo de la paradoja, se presenta un antes y un después que apunta a un proceso de transformación llevado a cabo por el Conde Duque, a quien se refiere el escritor solo con el título de Conde ${ }^{46}$ : «Yo no soy / ha deshecho; yo me era / me tenía; hoy soy / he dejado de ser». Igual sucede cuando hace referencia a su calaña: "He sido», "habiendo dejado de ser», "no soy», "he dejado». Esta configuración de la etopeya plasma los atributos de un Quevedo presente, pero a los que se suman los de un Quevedo pasado; es decir, en la descripción realizada de sí mismo en un momento concreto se perciben los cambios sufridos en un periodo, cuyos márgenes temporales abarcan desde antes de llegar Olivares a la vida del escritor hasta este año de 1633, cuando escribe a la condesa ${ }^{47}$.

Tres elementos más contribuyen a la configuración del autorretrato: su nacimiento y linaje, de los que se vanagloria, pues le definen como cristiano viejo a la par que trae a colación las acciones y atributos por los que son recordados sus ascendentes («me honran con su memoria»: la memoria de una familia entregada al servicio de la monarquía desde tiempos de Felipe II). No pierde ocasión para señalar a la condesa que ambos son cristianos viejos, pues ella desciende en línea directa de los reyes de Navarra. Solo cuando escribe sobre su nacimiento y linaje

45. Quevedo, Prosa festiva, pp. 462-463. Remitimos para este pasaje a Martínez Bogo, 2009 , pp. 349-350, quien ya destacó su “claro matiz humorístico», amén de señalar los recursos retóricos de los que se vale Quevedo en él, y a Hermès, 2014, p. 554-555, quien también ha abordado su comentario.

46. Al título de conde de Olivares, Gaspar de Guzmán, sumó el de duque de Sanlúcar en el año 1625, fue a partir de este año cuando se hizo llamar conde duque. Quevedo en otras cartas, dirigidas a Francisco de Oviedo tras la muerte de Olivares $(1,6,15$ y 29 de agosto de 1645) también se refiere a don Gaspar solo por el título de conde (Quevedo, Nuevas cartas, pp. 184, 185, 187 y 189). No se debería de descartar la opción de que con ello se oculte una intencionalidad crítica por parte de Quevedo.

47. Iriarte López, 2004, p. 133: «Para hablar de retrato ha de existir [...] una suspensión temporal, una puntualización estática, una representación que se sustrae [...] conscientemente al discurso temporal. Todo retrato es una escena, o si se prefiere, una pintura, una mirada fija, un momento aislado, por amplios márgenes temporales». 
abandona el tono humorístico y perfila este atributo con el verbo «ser» en presente y en oraciones afirmativas. Nos planteamos si es posible que, sin ser mencionados explícitamente, aluda a (otros» que, al contrario que Quevedo y la condesa, no pueden presumir de limpieza de sangre, al ser excluidos de esa observación cómplice que lanza a doña Inés de Zúñiga: «frasis que entenderá su excelencia» y no podrán entender "otros» que no tengan igual origen, como es el caso del conde duque. Este fragmento fue comentado por Sancho de Sandoval en la Respuesta que dio a la carta en los términos siguientes:

En cuanto a su particular, y a lo que dice de sí v. M. con tan modesta galantería, y puede con seguro de que a otros a quien hacemos reverencias mayores que las suyas invidiarán en lo personal todos, y en la sangre muchos ${ }^{48}$.

Sobre este asunto, recuérdese que unos meses después pone fecha a Execración contra los judios, memorial dirigido al rey Felipe IV en el que pide la destitución de Olivares, a quien acusa de querer suavizar los estatutos de limpieza de sangre, de fomentar el ascenso social, político y económico de los judíos, de ser judío y, finalmente, de ser responsable de la ruina y desastres que asolan la monarquía.

Finalmente alude a su hacienda, al que ha ligado la edad, descritos ambos en relación inversa a través de los opuestos «más» y «menos» y con los que recobra el tono humorístico.

Más allá de ofrecer el autorretrato de un hombre en busca de esposa, Quevedo dibuja uno de lo que parece, no es, es y cuenta, y a la vez elabora una categorización de la descripción: 1) los aspectos físicos: apariencia, es decir, lo que otros perciben de él; 2) las relaciones cortesanas: lo que no es, pues las circunstancias le obligan a hacerse y deshacerse a capricho del poderoso; 3) los aspectos morales: lo que es por decisión propia; 4) origen y linaje: lo que es por nacimiento y herencia y, por tanto, invariable; imposible de moldear por otros, cambiar uno mismo u ocultar y transformar a ojos de los demás, y 5) la edad y el dinero: lo que desea hacer creer a otros.

En definitiva, el retrato que pinta de sí mismo Quevedo en la carta a la condesa de Olivares supera la simple burla para alcanzar una complejidad que es fiel reflejo de las diversas caras que presenta el hombre en sociedad, $y$, a diferencia de la breve prosopografía integrada en el relato del viaje a Andalucía - carta a Velada-, este retrato, donde se han fusionado la prosopografía, la etopeya y otras dimensiones socio-culturales que delimitan el contorno como individuo de Quevedo, constituye por sí mismo un texto independiente que mueve al lector hacia la reflexión.

Presentamos un tercer y último autorretrato diferente a los dos anteriores. Se escribe desde el convento prisión de San Marcos de León,

48. BNE, ms. 20274 / 3, fols. 2 v y $12 \mathrm{v}$. 
poco antes de ser excarcelado ${ }^{49}$. Lo leemos en una carta, fechada el 8 de junio de 1643, dirigida a Diego de Villagómez, militar que había luchado en el ejército español de Flandes y que abandonó las armas para ingresar en la Compañía de Jesús ${ }^{50}$. El motivo de la carta es dar el parabién al que fue alférez por lo acertado de su decisión. El retrato se distribuye entre el exordio ${ }^{51}$, con el que se ganará la buena disposición del militar retirado, la narratio, donde expone los errores cometidos, y en las líneas inmediatas que preceden a la petitio.

Señor don Diego: Yo, que soy el escándalo, escribo a v. M., que es el ejemplo; y siendo tan diferentes, encaminamos a los otros a un mismo fin: yo, en que nadie haga lo que yo he hecho, y v. m. en que todos hagan lo que hace. Tanto se sirve la virtud, del horror que da el malo para escarmiento, como de la virtud del bueno para el crédito $^{52}$.

Como decimos, las primeras notas de su retrato se hallan al inicio de la carta, el autorretrato lo irá perfilando de forma progresiva a lo largo de la misma. La semblanza del escritor se dibuja en paralelo y a través de contrarios a la de Villagómez -«yo, que soy el escándalo» / «v. m., que es el ejemplo»; (yo, en que nadie haga lo que yo he hecho» / (v. M. en que todos hagan lo que hace»-, representando el escritor la cara censurable y el militar la virtuosa. Aun así, a pesar de ser uno el haz y el otro el envés de la moneda, el comportamiento de ambos confluyen en la misma meta, ser paradigma moral: "y siendo tan diferentes, encaminamos a los otros a un mismo fin»; (Tanto se sirve la virtud, del horror que da el malo para escarmiento, como de la virtud del bueno para el crédito» ${ }^{53}$.

En la pintura que aquí Quevedo realiza de sí mismo va a tener una gran importancia las acciones realizadas en el pasado y el tiempo y esfuerzos empleados en ambiciones vanas, pues unos y otros contribuyen a la configuración de su presente semblanza, trazada siempre la del escritor al hilo que perfila la del nuevo jesuita. Contemplamos un autorretrato de Quevedo y un retrato de Villagómez que hablan a la vez

49. Esta es la última carta escrita desde San Marcos de León con data: «De la prisión, hoy de 8 de junio de 1643); sobre la fecha de esta carta léase la nota de Crosby en Quevedo, Nuevas cartas, pp. 282-283. En la segunda quincena del mes de junio tuvo que ser puesto en libertad y ya algo antes del 9 de julio de ese mismo año escribe a Francisco de Oviedo fuera de la cárcel (Quevedo, Nuevas cartas, pp. 131-132). Puede leerse un extenso comentario sobre la carta a Villagómez en Crosby, 2001.

50. Quevedo, Nuevas cartas, pp. 130-131, también véanse las pp. 282-283 para la fecha de la carta y Diego de Villagómez.

51. En esta ocasión, la carta consta de las cinco partes preceptivas: salutatio, exordio, narratio, petitio y conclusio.

52. Quevedo, Nuevas cartas, p. 130.

53. El empleo del paralelismo y la antítesis en las descripciones de personajes son moneda común en la obra de Quevedo, como bien demostró Azaustre, 1996. Así mismo sucede en las cartas que estudiamos dirigidas al marqués de Velada y a la condesa de Olivares, analizadas en detalle por Martínez Bogo, 2009, pp. 345-354, por lo que creemos que no es necesario incidir más en ello. 
de sus pasados y presentes, lo que deja entrever el profundo cambio sufrido en un periodo temporal indefinid ${ }^{54}$; aunque no puede afirmarse que se describa en ellos un proceso evolutivo de Quevedo o de su corresponsal, puesto que, como explica Iriarte López (2004, p. 154), «el retrato, por naturaleza, es estático, y es precisamente esta concreción o 'a-temporalidad' la que permite la idea de un brusco cambio de estado, la que puede mirar lo que 'ya no era'». Quevedo, al dejar «mirar lo que 'ya no era'», también apunta hacia un cambio implícito causado, en parte, por el cansancio, arrepentimiento y desengaño:

Alta y descansada seguridad es esta para quien ha padecido las envidias de los hombres y las trampas de la fortuna. El soldado que se vuelve a Dios y deja los ejércitos por el Dios de los ejércitos, asegura el oficio, no le abandona. La mayor valentía es el huir del furor de las batallas a esta paz, contra más enemigos belicosa. Mucha sangre y no poco sudor me debe aquella locura armada, que por más de veinte años me vendió la vida a la rabia de los mares y al desatino vanaglorioso de campañas y sitios, que me dejó un arrepentimiento tardo, el cuerpo inútil y la codicia burlada. Quedé tan pobre como si hubiera vivido bien, y tan delincuente como si hubiera robado el mundo. Vi cobrar este propio estipendio a los grandes señores que vi mandar las armas; $y$ a los que ensordecieron con rumor la tierra fueron amenaza de grandes poderíos, les fue postrera cláusula de la vida, cárcel desacreditada. (Recorra v. M. su memoria y hallará cementerios de ilustres cadáveres, y horribles con los huesos y prisiones de los que acompañó o le dieron órdenes).

Solo v. m. ha logrado este desengaño, pues deja la compañía de que es capitán, por ser soldado de la compañía de Jesús, cuyo teniente es el glorioso patriarca san Ignacio ${ }^{55}$.

Solo cuando llega el momento de finalizar la carta, obtenemos la información que ayuda a completar la imagen de un hombre agotado por años de cárcel, enfermo y pobre; sin abandonar los paralelismos -«lástima» / «envidia»; «compañía» / «soledad»- que han dominado toda la epístola:

Hoy cuento, señor don Diego, catorce años y medio de prisiones, y en la cárcel nueve heridas en que cuento el jornal de mi perdición. Téngame v. M. lástima en pago de la envidia que le tengo, y pues Dios le da mejor compañía, gócese en ella sin la soledad del amigo, que en poder de la persecución yace tan alcanzado de cuenta ${ }^{56}$ que aun paga menos de lo que debe ${ }^{57}$.

54. Crosby (Quevedo, Nuevas cartas, p. 283) cree probable que Quevedo haga aquí referencia a los años en los que estuvo al servicio del duque de Osuna y a los desengaños y prisiones sufridos después y a la publicación de sus obras (1613-1634, "poco más o menos»).

55. Quevedo, Nuevas cartas, pp. 130-131.

56. Alcanzar de cuenta: «Quedar con acción o crédito con una persona, por no haberle pagado todo lo que se le debía» (Aut).

57. Quevedo, Nuevas cartas, p. 131. 
En esta última descripción no han sido suficientes la etopeya y la prosopografía; elementos ajenos a los morales o físicos, como las acciones o acontecimientos presenciados o realizados, el paso del tiempo, la prisión y la enfermedad han sido necesarios para completar la descripción de sí mismo. Al igual que el trazado en la carta a la condesa de Olivares, este retrato incita a la reflexión, pero si el anterior nos presentaba al hombre en sociedad, en este nos ofrece de forma insistente a un hombre agotado y arrepentido de haber vivido entregado a ideales equivocados. Para la comprensión global hay que atender a las circunstancias que marcan su vida presente -«hoy»-, donde el tiempo, medido en la exagerada cifra de «14 años de prisiones $)^{58}$, y el estipendio, contabilizado en «heridas», rematan la representación de sí mismo que desea comunicar a su corresponsal: un hombre perseguido, en la cárcel, solo y enfermo.

\section{Figuras}

Por el epistolario de Quevedo pasean una gran variedad de personas contemporáneas al autor, de las que unas pocas son convertidas por su pluma en figuras que regala al destinatario. El hombre de la corte o de la aldea es objeto de risa para los lectores de sus cartas y bosqueja sus semblanzas con los mismos recursos que utilizó para el elenco de figuras que desfilan por los entremeses, como ya explicó Eugenio Asensio:

El escenario se puebla de humanidad urbana, constelación grotesca unificada bajo el nombre de figuras, que con la comunicación de vida y teatro, de poesía y cotidianeidad, tan propia de nuestro Siglo de Oro, invaden de nuevo la calle donde los transeúntes las señalan con el dedo como criaturas escapadas del tablado ${ }^{59}$.

Este es el caso de dos individuos anónimos o sin relevancia en el entramado social de Quevedo: «La Portuguesa», criada del duque de Medinaceli, y «el Embustero», un timador que llega a la Torre de Juan Abad. Pero también convierte en personaje ridículo a un cortesano perfectamente identificado por su nombre, Bonifaz, perteneciente al círculo de conocidos de Quevedo y de su corresponsal, el marqués de Velada. Las caracterizaciones de los tres personajes se fundamentan en lo que son, en lo que hacen y dicen y en la presentación escénica como veremos a continuación.

La descripción de «la Portuguesa» la leemos en una carta de Quevedo en respuesta a otra del duque de Medinaceli, entregada en mano por

58. Crosby (Quevedo, Nuevas cartas, p. 283, n. 50) aclara que la cifra de catorce años y medio se refiere al tiempo total que pasó a lo largo de su vida en cárceles, en reclusión o en libertad limitada. Aunque considera este número exagerado, pues Crosby ha contabilizado que en total pasó 59 meses, es decir, algo menos de cinco años.

59. Asensio, 1971, pp. 83-84. 
la criada. La misiva del escritor está datada en Madrid, a 21 de diciembre de 1630, año en el que se inicia la correspondencia conservada entre ambos ${ }^{60}$. El desarrollo de la carta aborda los siguientes asuntos: $1^{\circ}$ descripción burlesca de «la Portuguesa» y confirmación de haber recibido la carta y el aguinaldo de Medinaceli; $2^{\circ}$ referencia a un señor no identificado; $3^{\circ}$ nuevas sobre el Casale; $4^{\circ}$ avisos sobre Felipe IV y don Fernando de Austria, el cardenal infante ${ }^{61}$, y rumores sobre posibles nombramientos; $5^{\circ}$ información críptica sobre «quien nos vendió el galgom, frase con la que hace referencia a una persona bien conocida por haber hecho una cosa mala y haberla cogido en ella $(A u t) ; 6^{\circ}$ noticia del embarazo de la duquesa de Medinaceli que comunica oralmente «la Portuguesa». Como el contenido demuestra, lo importante de la respuesta de Quevedo es dar cuenta de lo que pasa en la corte, de manera que la carta se acerca más a una de nuevas ${ }^{62}$ que a una jocosa, a pesar del retrato burlesco que traza de la criada con la excusa de hacer saber al duque que llegaron carta, buenas pascuas y aguinaldo con su propio. El retrato de la criada es el siguiente:

Señor, la Portuguesa llegó a mi casa con los gritos desde el Quemadero ${ }^{63}$; entró allí a media hora con aquella cara que yo he visto en pie de $\mathrm{cruz}^{64}$, rellenada sobre equis de dos huesos de muerto. Diome con una carta de vuecelencia buenas pascuas y aguinaldo. Luego empezó abriendo los brazos, a manera de milano contra clueca ${ }^{65}$, a correr por la sala diciendo alrededor:

60. Quevedo, Epistolario, pp. 246-248. La primera carta conservada de esta correspondencia no lleva data, Astrana la sitúa en 1630, antes del 11 de septiembre (pp. 235-236); Fernández Guerra en agosto (Quevedo, Obras, vol. 2, p. 547, n. a), anota: «La carta que publico en este sitio, copiada del original, se escribió por agosto de 1630, según autógrafo apuntamiento del duque».

61. A finales de 1630, el rey toma la decisión de enviar a los infantes don Fernando y don Carlos a Flandes y a Portugal respectivamente (Aldea Vaquero, 2008, p. 70); Quevedo solo menciona a don Fernando en la carta.

62. Sobre las cartas de nuevas véase Bouza, 2001, pp. 137-177.

63. No sabemos dónde se alojaba Quevedo en diciembre de 1630, para estas fechas ya ha adquirido casas en Madrid y el Quemadero, lugar donde ardían las hogueras y en ellas los condenados en los autos de fe -de ahí su nombre-, se hallaba en la glorieta de San Bernardo cerca de la Puerta de Fuencarral, bastante alejado de los inmuebles propiedad del escritor.

64. Calavera: "porque en el lugar donde Cristo fue crucificado, monte Calvario, había muchas calaveras de los que allí se crucificaban» (Cov.). Quevedo evoca la imagen de Cristo crucificado con una calavera al pie de la cruz (véase el cuadro de Velázquez, Cristo en la cruz, conservado en el Museo del Prado). También en Quevedo, Discurso de todos los diablos, 2005, p. 185: “calavera con calva de pie de cruz»; в 703, v. 49, у 748, v. 65.

65. Milano: «Ave de rapiña que tiene la cabeza llana, y en la corona hacia la cerviz, una mancha blanca, el pico corto y castaño obscuro, todo torcido, el cuerpo de color de hierro obscuro, los encuentros de las alas negros, los muslos desnudos, las uñas negras y torcidas, y la cola de horquilla. Es vocinglera y de aguda vista: vuela altísimamente dando giros y se esconde en las nubes. Habita en encinas y lugares cóncavos y pedregosos. Susténtase de carne de animales muertos y vivos, y de pescados. Es muy hambrienta, tragona y rapaz, y persigue las aves caseras, y con especialidad los pollos. Fue ave de mal agüero y vive más de ducientos años» (Aut). Compara a la criada con un milano con las alas abiertas 
«Oh, qué duque, qué gran señor! iTen tanta tierra, tantos pueblos, tantas ciudades!» Y de repente, plegándose toda y hincada de rodillas, decía: «El duque mi senhor, o môr senhor do mundo». Y respingando, mudando la habla en chillido, y incensando ${ }^{66}$ con los brazos decía: «Deime tanto trigo, muito trigo, venho rica»; y mudando de trote, decía: «Acevedo (por Quevedo), por los montes andaba con elle a caballo, a horcajada, a caza»; y diciendo esto y haciendo el caballito, trotó toda mi sala. Luego, haciendo un ovillo el varapalo de su talle, decía: «beis a Casa do Campo, y as Laranjeiras, y ese Diablo? (yo entendí el Pardo), tudo e merda en comparazõn del Manojil». Y de buen desvío, de tal suerte mudó tonos y desquició su cuerpo, que yo y dos amigos que se hallaron aquí quedamos desvanecidos de la vista y atronados de los oídos, y ella ronca; y como es, con estallido, se fue diciendo: «Escribid, Acevedo, para el sábado, que he de enviar todas as respuestas a aquelle rey del mundo».

[...] Olvídaseme que embistió conmigo, diciendo: «O duque meu senhor me dio este abrazo que te diese»; y cerró conmigo ${ }^{67}$; y con una cesta que traía me aplastó las narices, y con la cara me sahumó de rancio ${ }^{68}$.

Los primeros rasgos que caracterizan a la criada del duque son: su aspecto físico, la cara es representada como la de una calavera; otro el gentilicio que se utiliza como sobrenombre de la criada, y tercero, la voz chillona que se convierte en gritos, rasgo acentuado por la hipérbole («llegó a mi casa con los gritos desde el Quemadero; entró allí a media hora»). Sobre estos aspectos se va a desarrollar la pintura de esta figura, donde la prosopografía junto a otros rasgos como el habla o el olor se imponen a la etopeya.

La construcción de esta figura grotesca se fundamenta en la acumulación de imágenes y en el diálogo, construido este con una lengua deformada entre española y portuguesa ${ }^{69}$. Quevedo descubre la animalidad, primero de milano y luego de caballo, que se oculta en la personalidad de la criada tras el físico, las acciones, la voz, el olor y los

lanzándose hacia su presa, una gallina. Nótese como la detallada descripción del milano se ajusta a la perfección con varios de los rasgos atribuidos a las criadas.

66. Quevedo juega con los tres significados del verbo incensar: Ofrecer el incienso o el humo del incienso; en el sentido moral, dar honra excesiva, las más veces por adulación; analógica y metafóricamente vale andar de aquí para allí, haciendo u diciendo alguna cosa, tomada la semejanza del modo de incensar $(A u t)$. La criada mientras va de un lado a otro de la casa de Quevedo, pondera la grandeza y virtudes de Medinaceli, expeliendo olor corporal.

67. Cerrar conmigo: Arremetió contra él con denuedo y furia (Aut). Autoridades ejemplifica el significado de la expresión “cerrar con alguno» con Visita de los chistes, con el pasaje donde aparece Diego Moreno.

68. Quevedo, Epistolario, pp. 246-247. Sahumar: Dar humo a alguna cosa para purificarla o para que huela. Le impregnó de su rancio olor. в 697, v. 28.

69. El portugués fue una figura eminentemente cómica de los entremeses de los Siglos de Oro, cuyos rasgos más destacables son su carácter enamoradizo, su fanfarronería o arrogancia y su condición de músico; parte de su caracterización se basó en lengua portuguesa que era parodiada y deformada, además de entremezclada con la castellana, tal como hace Quevedo en la carta dirigida a Medinaceli. Véase Borrego, 2015. 
gestos $^{70}$. El escritor sitúa a la criada en un lugar concreto -la sala de su casa-, del que se sirve para describir sus rápidos movimientos a la vez que se trasmuta y habla, todo ello ante un público compuesto por el escritor y dos amigos que al ver aquellas metamorfosis corpóreas y vocales pierden el sentido. Quevedo ha creado una escena de gran potencia visual, con imágenes grotescas de una criada vocinglera que le ha ofrecido la realidad misma. El proceso de creación de esta figura es el mismo que el descrito por Emilio Orozco:

En los versos de tema satírico burlesco el autor se recrea como pintor en la invención imaginativa de figuras monstruosas y grotescas, con violentas metáforas de trasmutación descendente y degradante, muchas veces en rápida sucesión acumulativa que reitera hiperbólicamente el intencionado rasgo deformador caricaturesco de lo humano. [...] Quevedo ofrece sobre todo visiones estáticas que apenas vemos en acción, aunque la rapidez con que se suceden en su enumeración preste al conjunto de metáforas acumuladas un aparente dinamismo y movilidad ${ }^{71}$.

En la figura de «la Portuguesa» vocinglera, percibimos un constante movimiento sugerido, además de por la cadena de símiles entrelazados, por una descripción apoyada en el diálogo (reiteración del verbo decir) y erigida sobre una narración que hila una sucesión de oraciones con valor modal -basado en el gerundio- para la expresión de las mutaciones físicas sufridas por la criada. Quevedo hace hablar, gritar, trotar, etc. al nuevo ser que surge del cambio: «abriendo los brazos»; «diciendo alrededor»; "plegándose toda y hincada de rodillas, decía»; «respingando, mudando la habla en chillido, y incensando con los brazos decía»; «mudando de trote, decía»; «diciendo esto y haciendo el caballito, trotó toda mi sala»; «haciendo un ovillo el varapalo de su talle, decía». Así el retrato se compone de una suma de gestos y movimientos que convierten a «la Portuguesa» en un ser ridículo y extravagante. Con esto y la localización espacial, Quevedo ha vivificado un suceso ante los ojos de Medinaceli, dotándolo de ritmo, y gracias a la acumulación de los sucesivos rasgos expuestos en breves frases junto al estilo directo.

Las sucesivas metamorfosis son expuestas en un orden temporal que provocan sorpresa en el lector, marcado con los siguientes términos o expresiones: "a media hora», «luego empezó», "de repente»y «luego». Así pues, es una mujer que en un breve espacio de tiempo, en la sala de

70. Quevedo gusta de caracterizar a algunos personajes con rasgos de animales, estos a veces presentes incluso en sus nombres, como sucede con "Grajal» y "Corneja», moza y ventero del entremés La venta. Asensio, 1971, p. 181, ya señaló que «la animalidad escondida tras lo humano ha servido de nota sugestiva a Quevedo en numerosos pasajes, especialmente en El Buscón y el entremés de La ventas. Véase también p. 231. La calavera o el caballo son lexemas que Quevedo asocia a la mujer: el primero representa la vejez y anuncia la muerte, el segundo aporta connotaciones de animalización (Schwartz, 1984, pp. 41 y 60). El milano también es lexema frecuente en su obra con el que representa la rapiña.

71. Orozco, 1982, p. 419. 
Quevedo y ante él y sus acompañantes, ha sufrido un continuo proceso de cambio que no ha finalizado hasta el momento de abandonar la casa del escritor, ya que la última mudanza se produce cuando se despide de él; entonces «la Portuguesa» se convierte en un ser que embiste, cierra e impregna al escritor de un rancio aroma. El contexto espacio temporal es, por tanto, un elemento más que ha contribuido a la creación de esta descripción.

El objetivo primero de esta misiva es confirmar al duque que el propio que ha de entregar a Quevedo su carta y presente ha realizado el encargo correctamente. Sin embargo, con el fin de divertir y atraer la atención de su corresponsal, antes de dar cuenta de los asuntos que comparten y de las nuevas que circulan por la corte, el escritor dibuja una figura en la que despliega sus mejores artes literarias. Ha convertido a la criada en un ser grotesco y moldeable que sufre, ante sus ojos y los de dos amigos, múltiples transformaciones que se manifiestan mediante el habla -grita, chilla, habla en español y en portugués, etc.-, los gestos y los movimientos del cuerpo. Medinaceli va a ver a su criada abandonar la forma humana y adoptar la de milano y después pasar de milano a caballo, para terminar como ovillo y ser indefinido con capacidades propias de personajes mitológicos o fantásticos, puesto que esta grotesca mujer tiene el poder de privar de sus sentidos a los que la ven y oyen. Y gracias a este pasaje, una sencilla misiva ha sido mudada en una ejemplar muestra del ingenio y agudeza quevedianos, en la que ha puesto en práctica las lecciones aprendidas de Teofrasto, cuando en primer lugar concreta la peculiaridad destacada de la criada a través de una breve frase: «la Portuguesa», rasgo acentuado por los diálogos en los que Quevedo remeda el habla portuguesa, a continuación, en tercera persona, sigue la visión de la mujer, no su prosopografía o etopeya, sino en una retahíla de detalles de su comportamiento, tal como lo explicó Asensio sobre los caracteres de Teofrasto:

Teofrasto empieza cada capitulito con una sucinta frase que deslinda el carácter correspondiente: el taimado, el lisonjeador, el charlatán, el supersticioso, el podrido, el enfadoso, el fanfarrón, el cobarde, etc. Tras la sumaria aclaración sigue en tercera persona una visión concreta del tipo contemplado no en su mecanismo psicológico, ni en la lógica de su tacha o vicio, sino en una retahíla o enumeración de pormenores objetivos de su conducta: gestos, comportamiento en determinadas situaciones, acciones y frases peculiares, que pincelada tras pincelada bosquejan los contornos de su figura moral y social ${ }^{72}$.

También podría haberse incorporado a la pléyade de figuras ${ }^{73}$ de la obra de Quevedo “el Embustero», un estafador protagonista de buena

72. Asensio, 1971, pp. 184-185; véanse también las pp. 186 y 187.

73. Quizás sería más adecuado denominarlo «flor», ya que, como afirma Azaustre (Quevedo, Vida de corte, p. 316), “Flores” retratan a individuos que tienen en común vivir 
parte de la carta que escribe Quevedo en la Torre de Juan Abad, el 12 de abril de 1638, a Sancho de Sandoval ${ }^{74}$. La misiva, como la anterior, se escribe en respuesta a una de don Sancho. Los asuntos que en esta carta se tratan son: $1^{\circ}$ Se congratula de que Sandoval se haya recuperado de una enfermedad; $2^{\circ}$ da cuenta de la correspondencia que comparte con el triángulo formado por Sandoval, don Alonso Mesía de Leiva y el duque de Medinaceli; $3^{\circ}$ alude a don Alonso; $4^{\circ}$ narra la anécdota del «Embustero»; $5^{\circ}$ escribe sobre Juan de Chaves; $6^{\circ}$ noticias sobre Francia, Italia y Portugal; $7^{\circ}$ informa sobre una cédula que ha salido de su majestad por la que los curas pueden solicitar información de nobleza.

La anécdota del «Embustero» la narra a petición de Sandoval y, como puede leerse, la figura se bosqueja sobre rasgos y acciones objetivas, en los que no se perciben desviaciones humorísticas, hiperbólicas o grotescas debidas a la pluma creadora de Quevedo. En esta ocasión, el escritor se limita a describir la realidad según se la han contado, puesto que Quevedo jamás ha visto al «Embustero»:

El «Embustero» es el más superlativo que se ha visto. Él lleva una maleta atestada de hábitos de Santiago, Calatrava y Alcántara, Avis, Montesa, Christus, de San Esteban de Florencia, de San Miguel de Francia, de San Juan, de la Nunziata de Saboya y de San Antón ${ }^{75}$, y en cada lugar es diferente caballero, diferente nombre y apellido y pariente, con diferentes cargos y ocasiones de viaje. Los criados siempre van delante u a negocio, y él siempre solo. En todos los lugares va vendiendo trigo y cebada a la tasa, que libra en los que deja atrás seis o ocho leguas, porque haya tiempo para desparecerse.

Síguese a su descripción la historia. Aquí llegó solo en su mula, con su fardo de hábitos, y puesto uno de Alcántara. Dijo era hermano de la señora gobernadora de Villanueva; llamábase don Pedro Sarmiento, que iba con unas pruebas a Córdoba. Preguntó por sus criados; dijéronle no habían llegado. «No es eso -dijo-. Yo dije había de pasar a la venta, y estarán allá; mas yo no pienso cansarme; aguarden los pícaros». Mandó al güésped diese recado a su mula; fajose la cara con una bigotera; preguntó si estaba yo en el lugar, dijéronle que sí y dijo: «Es gran caballero. Harto se holgara de verme; mas, güésped, chito, y perdone el amigo hasta la vuelta, que vendré con mi gente». Preguntó: «¿A cómo pesa la cebada?». Dijo el mesonero que a 15 reales, y no se hallaba. Y él luego: «Algo le ha de valer ser yo su güésped. Si quiere treinta fanegas, yo le daré libranza de ellas en Villanueva. Darme a cien, y lo demás al que le dará mi cebada a la tasa». El mesonero es prieto, y respondió: «Más necesidad tengo de que v. M. me pag[u]e la que comerá la mula y la cama que de otra cosa». Con esto pagó, y se fue.

de la trampa y el engaño». n. 432 .

74. Quevedo, Cartas, pp. 292-295. Un resumen del pasaje puede leerse en la p. 294,

75. Todas son órdenes militares - españolas y extranjeras- fundadas durante la Edad Media, excepto la de San Esteban de Florencia que fue creada por Cosme I de Medici en el siglo xvi. Corrijo puntuación, pues una orden es la de San Juan y otra diferente la de la Santissima Annunziata de la casa de Saboya. 
En Villacarrillo, en el mesón, topó unos hombres de aquí y de Cózar. Preguntoles de dónde eran; dijeron: «De la Torre», y replicó: «Allí está mi hermano, don Francisco de Quevedo; allá he de ir desde aquím. Convidoles con cebada a la tasa si le daban cien reales. Diéronselos, y dioles una libranza en un don Jacinto, de Villanueva del Arzobispo, y una carta para mí; fueron a Villanueva del Arzobispo, y el don Jacinto los desengañó. Trujéronme mi carta; el sobreescrito: "A don Francisco de Quevedo Villegas, mi hermano», etts. La carta, preciosísima, y firmaba: «Don Diego de Quevedo Villegas». Queda v. м. informado de las andanzas del pringón ${ }^{76}$.

El relato acerca de este individuo se estructura en dos partes que marca el propio Quevedo: «la descripción» del modus operandi del “Embustero» y «la historia» de dos sucesos, uno se desarrolla en la Torre de Juan Abad y otro en Villacarrillo. La «historia», destinada a complementar la «descripción», ofrece todo tipo de detalles cuya finalidad es perfilar minuciosamente la calaña del individuo $y$, por tanto, el carácter $^{77}$ del «Embustero».

En la «descripción», Quevedo, a modo de apertura, incide en la característica sobresaliente del individuo: el engaño, y lo hace a través de tres elementos: $1^{\circ}$ El apodo por el que se le conoce - Embustero»-, $2^{\circ}$ la definición en sí misma: “es el más superlativo», $3^{\circ}$ el refuerzo que recibe el atributo «superlativo» del adverbio «más». A partir de aquí Quevedo enumera, como hemos dicho, las artimañas empleadas en el embuste, por lo que todo lo que sigue es la amplificación de la definición: “El Embustero" es el más superlativo que se ha visto». Esas artimañas se fundamentan en la apariencia, de ahí la necesidad de nombrar todos los hábitos de las órdenes militares de los que se sirve para llevar a cabo sus fechorías. Para cada lugar tiene un hábito, nombre, apellidos, parientes, cargos y motivos que explican el viaje. Trabaja solo, pero tiene que justificar que no le acompañen criados para completar la falsa imagen de caballero. Quevedo, pergeñado el retrato del sujeto, explica cuál es el engaño del que se vale para sacar el dinero a los incautos.

Así pues, Quevedo comienza con una escueta oración que dibuja perfectamente al individuo y luego introduce, en tercera persona, una semblanza formada de detalles que hablan de su forma de actuar. Otra vez, aplica la técnica descriptiva aprendida de Teofrasto que ya utilizó en el desarrollo de otras figuras, pero ahora lo hará sin añadir recursos o elementos deformadores de la realidad. En esta ocasión, describe al lector la realidad de forma objetiva.

76. Quevedo, Cartas, pp. 292-294. Pringón: «Puerco, sucio y lleno de grasa o pringue» (Aut). Por el contexto, Quevedo ha de emplear este término con el significado de embustero, mentiroso, embaucador o cualquier otro sinónimo o cuasi sinónimo. Aut ilustra este vocablo con un fragmento de la Hora de todos, perteneciente al cuadro del alquimista; en ese pasaje también tiene más sentido el significado de embustero que el de sucio.

77. Entiendo por carácter el conjunto de rasgos que, deducidos de la acción, son propios del sujeto retratado (Iriarte López, 2004, p. 135). 
La segunda parte del fragmento sobre «el Embustero», «la historia», es una nueva amplificación ahora muy por extenso, con la que, por un lado, concreta y, por otro, realza la «descripción» inicial. Nótese que la primera parte de la narración es la descripción del sujeto, construida con breves oraciones, en general yuxtapuestas, cuyo elemento inicial es un verbo, destacando con ello la acción que realiza el impostor. Estas oraciones, a modo de pinceladas sueltas, se corresponden con los rasgos de la apariencia que contribuyen a la etopeya: viaja sin compinches, en mula, con el hábito y nombre seleccionados, alude a un falso pariente, expresa el motivo del viaje y pregunta por los supuestos criados.

Tras la descripción del individuo que se incorpora al comienzo de «la historia», le sigue la pragmatografía o descripción de las acciones realizadas. Quevedo en este apartado alterna la narración en tercera persona con el estilo directo. Sandoval tiene así ante sus ojos la impostura de forma objetiva. Quevedo solo va a insertar un breve apunte acerca del carácter del mesonero a quien pretende engañar «el Embustero» - «el mesonero es prieto ${ }^{78}$ - con el que adelanta el desenlace final, el fracaso del timo en la Torre de Juan Abad.

El retrato avanza girando siempre en torno a los mismos elementos, añadiendo a esos componentes nuevos matices que presenta al lector en trazos sueltos. Para ello también se vale del estilo directo, lo que permite a Sancho de Sandoval, el destinatario de la carta, ver en acción al «Embustero» como si estuviese presenciando un entremés o comedia de figurón.

Aún se narra un suceso más, este se desarrolla en un mesón de Villacarrillo. Quevedo señala la procedencia de los individuos que serán víctimas del timo: uno de Cózar ${ }^{79}$ y otro de la Torre de Juan Abad. Este dato facilita al «Embustero» acomodarse a las nuevas circunstancias, lo que implica trocar de nombre y de parientes. Abandona el nombre de Pedro Sarmiento y adopta el de Diego de Quevedo; renuncia al parentesco con la gobernadora de Villanueva y abraza uno nuevo con el señor de la Torre, ya que en esta ocasión se presenta como el hermano de Francisco de Quevedo, detalle de su nueva personalidad que culmina con la redacción de una carta "preciosísima» que se entrega a Quevedo. El escritor es un elemento clave en la configuración del retrato del falso caballero que ha creado el «Embustero» para engañar a los hombres de Cózar y de la Torre de Juan Abad, pues el nombre elegido y parentesco fingido posiblemente han determinado el éxito de la impostura. La escena se levanta sobre los mismos pilares que la anterior: oraciones breves y estilo directo; en ambas sin asomo de sátira, ironía o humor.

El retrato de «el Embustero» ha sido elaborado con toda una serie de rasgos característicos de Quevedo, como es la alternancia de la narración en tercera persona y el diálogo; las enumeraciones acumulativas

78. Autoridades registra tres acepciones: negro, apretado y mísero, escaso y codicioso.

79. Cózar es una población muy cercana a la Torre de Juan Abad. 
frecuentes para las descripciones de los personajes, cuya finalidad ha sido hacer acopio de rasgos negativos y ridículos ${ }^{80}$. Esta descripción del «Embustero» bien podría ser de uno de los tipos o fantasías morales que moran en los Sueños o formar parte de las «figuras artificiales» o de las "flores» que habitan la Vida de corte y oficios entretenidos en ella ${ }^{81}$, cuando Quevedo se transforma en el «Teofrasto del hampa cortesana $)^{82}$.

Hallamos en la carta sobre el viaje a Andalucía ya mencionada varios individuos que podrían considerarse figuras tras pasar por la pluma de Quevedo. Destacamos el caso de Gaspar de Bonifaz, cortesano relacionado con el círculo social del escritor y del marqués de Velada en torno al año 1624, momento en el que acompaña al rey Felipe IV en su papel de caballerizo real, en el viaje a las Andalucías organizado por el conde de Olivares. Por tanto, la diferencia principal con los dos anteriores individuos, «la Portuguesa» y «el Embustero», reside en el estatus social de Bonifaz y en la relación existente entre este sujeto, Quevedo y su corresponsal ${ }^{83}$. El escritor detalla con cuenta gotas los pormenores que dan forma a la personalidad de Bonifaz, según avanza el relato de esas primeras jornadas del viaje a Andalucía, primero en Tembleque, después en Madrilejos (en la provincia de Toledo, a medio camino entre Tembleque y Membrilla, y no Madrigalejo, en Extremadura) y por último en Linares:

80. Azaustre, 1996, p. 79, destaca su empleo en los sueños y fantasías morales con esta misma finalidad. También explica con todo detalle como la enumeración junto con el paralelismo, en sus distintas modalidades, se convierten en los recursos más frecuentes y efectivos en obras como los Sueños o el Buscón, donde la inclusión de figuras o tipos sobre los que recae la aguda sátira de Quevedo es habitual.

81. Quevedo caracteriza a las «figuras artificiales» por cuidar su aspecto: «Hay figuras artificiales que usan bálsamo y olor para los bigotes, jaboncillo para las manos y paletilla de cera para los oídos» (Vida de corte, p. 323); también el engañoso personaje del «Embustero» cuida de su apariencia física: "fajose la cara con una bigotera». Varias «flores» corresponden a personajes que de alguna forma viven de engaño.

82. Asensio, 1971, p. 184.

83. Lo situamos cercano a Velada por lo que dice Quevedo sobre unos negocios del marqués: «Bonifaz ha hablado con el señor Araciel de los negocios de vuecelencia; y él y yo somos servidores de vuecelencia y suyo, y a su disposición, y cofrades del diente» (Quevedo, Prosa festiva, pp. 379-380). Gaspar de Bonifaz nació en Yepes (Toledo), ganó fama como diestro en el arte taurino, fue autor de unas Reglas de torear que dedicó al conde duque de Olivares, impresas en Madrid, Oficina Tipográfica de Ricardo Fe, a costa de Francisco R. Uhagón, 1887. Fue también autor Del arte de andar a caballo, impreso en 1635 según Nicolás Antonio, quien afirma de Bonifaz haber sido muy conocido en Madrid durante el reinado de Felipe IV. También escribió algunos poemas -el ms. 18405 de la BNE, letra siglo XVIII, copia unas redondillas atribuidas a Bonifaz- por lo que fue celebrado en el Laurel de Apolo de Lope de Vega (silva viII, v. 394). Fue espía mayor y superintendente general de las inteligencias; la BNE conserva el ms. 4163 con la correspondencia entre Juan de Torres, teniente general de espía mayor en Barcelona, y Bonifaz (véase Navarro Bonilla, 2007). Para la relación de Quevedo con el marqués de Velada léase Pérez Cuenca y Campa Gutiérrez, 2017, pp. 1952-1958. 
En Tembleque recibieron a su majestad con fiesta de toros [...]. Bonifaz acertó alguno. [...] Y apareciéndosenos en la mesa del almirante, Bonifaz, caballerizo de los chistes del rey y guadaña de los guisados, nos recogimos.

El día siguiente fuimos a Madrigalejo [sic], donde Bonifaz se nos apareció entre los platos y tazas, diciendo: «Yo soy Bonifacio que todas las cosas mazco». [...]

Llegamos a Linares después de recogido el almirante. Cenamos lo que podimos escapar de Bonifaz. Fuime a acostar, y hallé que Bonifaz me había llevado una frazada ${ }^{84}[\ldots]$. Es cosa de ver venir a Bonifaz de noche haciendo los matachines ${ }^{85}$ del cenar y del dormir, con una candelilla en las manos, diciendo: «¿Tienen cama? ¿Han cenado?». Por él anda la cena movediza, y el estado fugitivo, y la cama en boleta, pel[1]izcando ${ }^{86}$ mantas de tal suerte, que para espantar los niños dicen: «Que viene la Bonimanta!». Grimaldos ${ }^{87}$ le acompaña. Y las más noches duerme de portante, ronca, sueña, dando audiencia: este es el hijo del hombre que no tiene donde reclinar la cabeza; come y cena de apercibimiento ${ }^{88}$, y pierde el juicio. [...]

Yo vengo sin pesadumbre y sin cama, y ha seis días que no sé de mi baúl. Dormimos a pares don Enrique y yo; hay cama de seis durmientes, y aún no se guarda de Bonifaz.

Es cosa de ver a [su majestad] con dos caballerizos, el uno Zapatilla y el otro Zapatón ${ }^{89}$.

Este es un caso claro en el que la descripción bosquejada por Quevedo está en dependencia con el destinatario. Bonifaz, Quevedo y el marqués de Velada, como ya se dijo, se conocen entre sí y muy probablemente los dos primeros prestan servicio al tercero. Esta circunstancia justifica el protagonismo que adquiere la persona de Bonifaz en la carta que escribe Quevedo a Velada y la descriptio que termina convirtiéndose en caricatura, en la que destaca el escritor una serie de atributos relacio-

84. Frazada: «Manta tejida de lana y peluda, que se echa sobre la cama» (Cov.).

85. Matachín: «Díjose de matar» (Cov.) por la danza de los matachines; esta se ejecutaba al son de una alegre música con cuatro, seis u ocho hombres disfrazados ridículamente con carátula y vestido ajustado de varios colores, esos hombres disfrazados se llamaban matachines (entrada de «matachín» en Aut). El matachín es una figura ridícula. Quevedo juega con la idea de matar el hambre y el sueño y con la vestimenta y movimientos de la danza de los matachines. En el Discurso de todos los diablos, 2005, p. 189 y 303, n. 232 , un pícaro es llamado «matachín de palacio» en un proceso paulatino de cosificación y en la Pregmática de los aranceles generales (Quevedo, Prosa festiva, p. 166 y n. 9), para la «reformación y reparo de costumbres, contra la perversa necedad», incluye a los que llevan "máscara de matachines» y hacen por dentro gestos. En в 654, v. 59, se aconseja a un «maridito matachín» que guarde a su mujer.

86. Boleta: cédula que se daba a los soldados cuando llegaban a un lugar para que fuesen a alojarse a la casa que les destinaba la justicia (Aut); pellizcar: hurtar y tomar parcamente alguna cosa comestible (Aut).

87. No hemos identificado a Grimaldos, quizás se trate de Francisco Martínez de Grimaldo, secretario del rey Felipe IV (Rivarola y Pineda, Monarquía española... Parte segunda, p. 276).

88. Bonifaz las más de las noches duerme de pie y come y cena de lo que va previniendo.

89. Quevedo, Prosa festiva, pp. 380-386. No nos detenemos a explicar en este fragmento las perífrasis descriptivas, dilogías o remedos y alusiones a refranes y pasajes bíblicos, para ello remitimos a Martínez Bogo, 2009, p. 346 y a la anotación de García-Valdés. 
nados con el nombre, ocupación, talante, actos y compañías. Los rasgos que le atribuye Quevedo parecen certeros, aunque pasados por el tamiz burlesco: Primero, en Tembleque, le describe como diestro en los lances taurinos, aptitud ya reconocida por Quevedo en otro lugar ${ }^{90}$; a continuación comunica a Velada que en este viaje es el donaire o gracioso del rey -«caballerizo de los chistes del rey»- y un glotón insaciable - (guadaña de los guisados»-, rasgo en el que insiste Quevedo cuando llegan a Madrilejos, aquí gracias al estilo directo es el mismo Bonifaz quien se presenta como figura ridícula - «apareció entre los platos y tazas, diciendo: "Yo soy Bonifacio que todas las cosas mazco" ${ }^{91}-$. Ya en Linares, sitúa ante los ojos de Velada al caballerizo del rey en la noche, como un fantoche extravagante.

El mismo Bonifaz, en Madrilejos, ha jugado con su apellido y lo ha transformado en Bonifacio (bonus > buen; fatum $>$ hado); en la parada siguiente de la comitiva, en Linares, ha sido Quevedo quien lo convierte en «Bonimanta». Esta vez es la parodia idiomática el recurso que contribuye a la construcción de la imagen del individuo, se trata en concreto de un neologismo por comparación condensada ${ }^{92}$. Para la ocasión, Quevedo cruza con el nombre de la persona, Bonifaz, el sustantivo manta, dando como resultado, en analogía con Marimanta ${ }^{93}$, el nuevo apodo y así el caballerizo mayor se convierte en una figura grotesca y fantasmal.

La transmutación de Bonifaz en fantasma nocturno ha sido progresiva, se anuncia con el verbo aparecer: (apareciéndosenos en la mesa del almirante» y «se nos apareció entre los platos y tazas», va adquiriendo forma cuando de noche, con la candela en la mano, vestido y moviéndose como un matachín va de un lado a otro, en busca de comida, cama y manta, hasta terminar su caricatura en «Bonimanta».

La caracterización implica a su vez ridiculización ${ }^{94}$ y aún Quevedo ha de destacar, para completar la «figura», los pies de Bonifaz, tan desproporcionadamente grandes que le permiten dormir de pie. Este rasgo sobresaliente de su físico le valió el apodo de Zapatón y en él incide Quevedo al formar el burlesco cuadro del rey Felipe IV acompañado de

90. Quevedo, Epistolario, p. 115, n. 2. Bonifaz y Velada participaron en la fiesta de toros con rejones celebrada en honor del príncipe de Gales, el año 1623, donde resultó herido el marqués; sobre este acontecimiento escribió Quevedo (в 673) unas décimas en las que alude a la participación de Velada (vv. 71-80, 91-100) y de Bonifaz (vv. 101-110).

91. Velada cuando responde a Quevedo, dice de Bonifaz que anda «hecho harpía» criatura mitológica que robaba la comida de Fineo-, por lo que este apelativo corresponde perfectamente con el retrato que el escritor ha bosquejado (Quevedo, Epistolario, p. 120).

92. Alarcos, 1955.

93. Marimanta: «Fantasma o figura espantosa, que se finge para poner miedo a los niños) (Aut).

94. La ridiculización de Bonifaz la ha percibido sin duda el marqués de Velada, quien escribe refiriéndose a él: «Déjele comer y beber, digo que coma, que en dejarle beber no sé si admitirá mi consejo; y no se burle mucho con él» (Quevedo, Epistolario, p. 120). 
sus dos caballerizos, ridiculizados al ser nombrados con los motes que corrían por la corte: Zapatilla y Zapatón ${ }^{95}$.

El diálogo se ha convertido en un elemento importante en la caracterización de los tres individuos de estas tres cartas, ha colaborado en la dramatización de las escenas narradas y ha contribuido al objetivo de presentar ante los destinatarios de las cartas a tres personas reales, directamente, sin el filtro del narrador, personas que bien podrían ser "figuras» $\mathrm{O}$ (flores» del corpus quevediano. La finalidad de recurrir al estilo directo en su correspondencia es declarada por el mismo Quevedo, en carta a Alonso Mesía de Leiva ${ }^{96}$, cuando cuenta un hurto ocurrido en una posada de Puerto Lápice. En un momento de la narración da paso al diálogo con las siguientes palabras: «No quiso, señor don Alonso, perder el tiempo la consideración, que, si atiende, en todo halla dotrina y estudio. Oíla su voz; y yo se la doy ahora, porque vuesa merced la oiga también y la logre mejors ${ }^{97}$.

Los pasajes dialogados implican una dualidad de actitudes, igual a la que Eugenio Asensio señaló cuando estudió los entremeses de Quevedo. Por un lado, la del personaje que declara su condición, virtudes, defectos, etc., y, por otra, la del creador que ridiculiza, censura o aplaude. Así pues, dejarles hablar ofrece matices que enriquecen en gran medida la narración del autor ${ }^{98}$. Pero además, en las cartas, Quevedo da forma a las tres figuras con una presentación escénica (espacio y tiempo) que el lector ha de valorar oportunamente: la escena de «la Portuguesa» se produce en la sala de la casa de Quevedo, en la Navidad de 1630, año en el que probablemente el escritor se pone al servicio de Medinaceli; con esta representación hilarante de la criada busca divertir al noble. La escena del «Embustero» se produce en la Torre de Juan Abad, esta se halla de camino a Beas del Segura, localidad donde se encuentra Sandoval, y en Villacarrillo, cerca de Beas, lo que explica el interés de Sandoval y la objetiva narración de los sucesos. Por último, las escenas protagonizadas por Bonifaz se desarrollan en las diversas localidades en las que para el rey y su comitiva camino de Andalucía, donde la escasez de viandas y los problemas con el alojamiento y falta de camas fueron constantes, junto con los percances sufridos en los desplazamientos a causa del mal estado de los caminos y las adversas condiciones climatológicas, lo que desde nuestro punto de vista encierra una crítica al viaje

95. Felipe IV se acompañó en este viaje de dos caballerizos, uno fue Francisco de Zapata, al que seguro llamaban «Zapatilla», el otro fue Gaspar de Bonifaz, conocido por el mote de «Zapatón». Teresa Julio, 2013, pp. 2, 9, 24 y n. 146, señala que Bartres se burla de los grandes pies de Bonifaz, quien se ha convertido en un "personaje de vejámenes». El marqués de Velada, cuando responde a esta parte de la carta de Quevedo, escribe: «no se burle mucho con él, pues sabe que siendo tan pródigo de pies, puede enterrar a uno de una patada y dejarle la suela por losa» (Quevedo, Epistolario, p. 120). Véase también Pérez Cuenca, 2016, p. 171, n. 8.

96. Quevedo, Epistolario, pp. 231-232.

97. Quevedo, Epistolario, p. 232.

98. Asensio, 1971, pp. 194-196. 
programado por Olivares, esperada por Velada, situado en la facción opositora al valido. Pero además, estas presentaciones escénicas, como señala Iriarte López ${ }^{99}$, son “una parte integrante de la caracterización» de los tres sujetos.

Bonifaz no es el único miembro de la comitiva real que va a ser descrito en términos burlescos por Quevedo, a este se le suma el licenciado Miguel de Cárdenas y Chincoya, alcalde de Casa y Corte:

Era de ver a don Miguel de Cárdenas con una hacha de paja en las manos, hecho cometa barbinegro, andar por los caminos como alcalde en pena, dando gritos.

En la caracterización de don Miguel son muy importantes los elementos que permiten una ubicación espacial y señalan la acción («ver; andar por los caminos; dando gritos») junto al objeto con el que se le describe (“una hacha de paja en las manos»), puesto que son los que permiten la descripción por analogía, primero «hecho cometa barbinegro» y a continuación “alcalde en pena». La conversión en personaje ridículo, en figura, del comisionado de abastos del viaje real, se produce por medio del calificativo «barbinegro», término con connotaciones negativas, unido a la idea de oscuridad y de «mal encarado» en otros textos de Quevedo ${ }^{100}$, y de la parodia de la locución “alma en pena», gracias a la que el alcalde de Casa y Corte pasa a ser “alcalde en pena» ${ }^{101}$, es decir, alcalde sin descanso posible por los muchos problemas de comida y alojamiento. García Padrón y Batista Rodríguez recientemente han comprobado cómo «en Quevedo la desautomatización deliberada de frases hechas es constante y conlleva conceptualizaciones complejas subyacentes en nuevos esquemas que se repiten a lo largo de su obra, constituyendo un universo fraseológico propio» que -añadimos- se prolonga en la correspondencia ${ }^{102}$. La descripción del comisionado confirma la crítica quevedesca a la organización del viaje viaje real programado por Olivares.

\section{Retratos}

En los tres retratos anteriores hemos visto que la presentación escénica coadyuva en su construcción. El lugar y el momento en el que ha situado a los sujetos retratados han contribuido a la recreación de los

99. Iriarte López, 2004, pp. 130-133.

100. Quevedo, Discurso de todos los diablos, p. 187: «Solo uno mal encarado, barbinegro, cara salpicada y zurdo»; Sueño del infierno, pp. 187, 195: “Tan presto se levantó un cochero viejo de aquellos, barbinegro y malcarado»; «Este es Judas-, y llegueme con codicia de ver si era barbinegro o bermejo»; B, núm. 630: «Este que, cejijunto y barbinegro / cornudo de mostachos, / lóbrego de color y anochecido".

101. Alarcos, 1955 , p. 27, recoge otros casos en los que Quevedo parodia esta locución, incluyendo “arrieros en pena» en esta misma carta (Quevedo, Prosa festiva, p. 383).

102. García Padrón y Batista Rodríguez, 2016, p. 122. 
caracteres del «Embustero» y de Bonifaz y a la prosopografía mutante de «la Portuguesa». Igual sucede con dos damas que aparecen en su correspondencia con el duque de Osuna y con el padre Pedro Pimentel, de la Compañía de Jesús ${ }^{103}$. Es de nuestro parecer que, en ambos casos, la presentación escénica sobresale por encima de otros elementos que bosquejan el retrato de las dos damas que siguen, veremos que el dónde y el cuándo en los que se sitúa a los individuos constituyen una parte integrante de la caracterización.

El 21 de noviembre de 1614, Quevedo escribe desde Madrid una carta a don Pedro Téllez-Girón de enorme interés, puesto que en una sola misiva se suceden diversos tipos de discursos y contenidos que corresponden con algunos de los servicios desempeñados por Quevedo para el gran duque de Osuna ${ }^{104}$. De ella ahora solo nos interesa el retrato que realiza de la camarera mayor, Catalina de Zúñiga y Sandoval, condesa de Lemos ${ }^{105}$ :

Fui a visitar de parte de vuestra excelencia a mi señora, la camarera mayor, e hízome grandísima merced, mostrándose muy agradecida a lo que vuestra excelencia la había escrito y a lo que yo la dije. Hallela sentada en una silla, escribiendo en un atril sobre una mesa llena de papeles, con un ferreruelo puesto. Representóseme un evangelista acaponado. Vive Dios que es notable señora. Dice que ha de gozar del ofrecimiento en todo lo que se ofreciere en Nápoles ${ }^{106}$.

Catalina de Zúñiga y Sandoval, esposa de Fernando Ruiz de Castro, VI conde de Lemos, grande de España, y virrey de Nápoles desde 1599 a 1601, hermana del duque de Lerma. Fue dama de la reina Ana de Austria, cuarta mujer de Felipe II. Sucede en el cargo de camarera mayor a la duquesa de Lerma, en el año 1603, después de su estancia en Nápoles, detalle que da sentido a las palabras de Quevedo: «Dice que ha de gozar del ofrecimiento en todo lo que se ofreciere en Nápoles». En el año 1611 pasó a ejercer el cargo de camarera mayor en la casa de sus altezas.

Como hemos leído, es de gran valor en la etopeya de la dama la representación escénica compuesta por los objetos que la rodean: silla,

103. La primera se conserva autógrafa y se fecha en Madrid, el 21 de noviembre de 1615; la segunda se escribe desde el convento prisión de San Marcos de León, el 11 de septiembre de 1642 (Quevedo, Epistolario, pp. 23-27 y Nuevas cartas, pp. 85-86). timos.

104. Existe un extenso trabajo sobre esta carta de Ettinghausen, 2006, al que remi-

105. Es imposible que esta camarera mayor sea la duquesa de Lerma, Catalina de la Cerda, como dice Ettinghausen (2006, pp. 80-81, aclara la confusión en 2011, p. 7, n. 16), puesto que había fallecido en 1603. Fue dama de la reina Ana entre 1571 y 1576 y camarera mayor con Margarita de Austria desde el 24 de diciembre de 1599 hasta el 22 de marzo de 1603, entonces dejó el cargo por su mala salud y le sucedió su cuñada, la condesa de Lemos (Martínez Millán y Visceglia, 2008, p. 809; y Fundación Casa ducal de Medinaceli).

106. Quevedo, Epistolario, p. 24. 
atril y mesa llena de papeles; la posición en la que es presentada: sentada; la acción que realiza: escribir; la vestimenta: ferreruelo ${ }^{107} \mathrm{y}$, por último, el instante concreto de recogimiento captado por la pluma del escritor, cuando la condesa, quizás despachando su correspondencia o entregada algún otro trabajo intelectual, es sorprendida por la visita de Quevedo. A la etopeya esbozada con la unión de todos los elementos expuestos, se suma la impresión subjetiva que la imagen ha suscitado en Quevedo: “un evangelista acaponado» ${ }^{108}$-símil que conlleva connotaciones masculinas y tal vez humorísticas-, y la objetiva afirmación: “es notable ${ }^{109}$ señora», con la que que alude de forma simultánea a su linaje y a sus virtudes.

La condesa de Lemos, persona principal en la corte de Felipe III, fue hija y esposa de grandes de España: sus padres fueron Francisco de Sandoval y Zúñiga, III conde de Lerma, IV marqués de Denia, e Isabel de Borja y Castro, por tanto, fue nieta del IV duque de Gandía, Francisco de Borja. Pero a la vez con el término «notable» desea hacer referencia a lo excepcional de su persona, a las virtudes intelectuales que merecen ser dignas de nota o atención. Por eso, la posible burla que podría deducirse de la representación de la condesa como una “culta latiniparla» ${ }^{110}$ queda anulada y, en su lugar, se erige la exaltación del linaje y valores de doña Catalina apoyada en el atributo «notable».

El lugar y el tiempo, en el que se integra el retrato de la princesa de Carignan, son también destacables por ser elementos que forman parte de la representación de la dama pergeñada por Quevedo, no de elogio -como en el caso de la condesa de Lemos-, sino de vituperio.

María de Borbón-Soissons, princesa de Carignan, esposa de Tomás de Saboya, hija de Carlos de Borbón, conde de Soissons; la princesa heredará el título de condesa de Soissons a la muerte de su hermano Luis, en julio de $1641^{111}$. El 4 de abril de 1636, el duque de Tursi comunica por carta al duque de Segorbe que el marqués del Viso llegó a Barcelona con cinco galeras de la escuadra de Sicilia, «dicen viene

107. Ferreruelo: “Capa algo larga» (Aut).

108. «Evangelista» aquí sinónimo de escribano o amanuense -recuérdese que en México se llama "plaza de los evangelistas» a la plaza de Santo Domingo, por ser este lugar donde ejercen su oficio los escribanos-; por ser mujer es acaponado, es decir, semejante a eunuco o capón, y también por llevar capa. Ettinghausen llama la atención sobre el hecho de que describa a esta dama en términos masculinos. Esta descripción nos recuerda a la pintura de Vermeer Dama en amarillo escribiendo (Galería Nacional de Arte de Washington).

109. Notable: Digno de atención; también grande o excesivo (Aut).

110. En la Carta de las calidades de un matrimonio, cuando describe a su esposa ideal, leemos: «Y si hubiese de ser entendida con resabios de catedrático, más la quiero necia; que es más fácil sufrir lo que uno no sabe que padecer lo que presume» (Quevedo, Prosa festiva, p. 463).

111. Cariñán o Cariñano son las formas del nombre de familia que utilizaron en el siglo xvir. Para la rama de la casa de Saboya, príncipes de Carignan, y para la rama de Soissons véase Moreri, El gran diccionario histórico, t. viII, p. 174. Tomás de Saboya unas veces luchó al lado de los franceses y otras, por ser contrario a Richelieu, al lado de los españoles. 
en ellas la princesa de Cariñano, mujer del príncipe Tomás, para pasar a Flandes» ${ }^{112}$. La princesa no llegó a la corte madrileña hasta el 15 de noviembre de 1636 y logró salir de España, donde fue retenida contra su voluntad, en $1644^{113}$. Intentó huir sin éxito en varias ocasiones, la última, según avisa Pellicer, en enero de 1642, quien apunta una anécdota pasada con la que destaca las conflictivas situaciones que protagoniza:

el viernes por la mañana la señora princesa de Cariñano nos dio otra alborada como la pasada, partiéndose de secreto con sus hijos y damas. Anduvieron locos los de la guarda y otros señores a buscarla. Vinieron a hallarla en Caramanchel, donde se está después de haber andado rodeando algunas leguas. Encontrola el gobernador de Aranjuez y, con toda su gente, anduvo por ellos a pie más de quince pasos, diciendo que si no la daban el coche se iría a pies, hasta que se le hubieron de dejar. Dicen no es cosa nueva, pues en el Piemonte, estando preñada, queriéndola detener su suegro la ida a Cariñán, donde estaba su marido, se salió a pie y anduvo tres leguas, hasta que la encontraron. Su majestad está muy sentido de esto, porque se cree que el señor príncipe Tomás no gusta que salga de Madrid ${ }^{114}$.

El día 11 de septiembre, Quevedo escribe a Pedro Pimentel sobre el posible traslado a León de María de Borbón; el 9 de octubre, comparte con el mismo corresponsal la noticia del traslado a Las Huelgas ${ }^{115}$, y, el 4 de diciembre, aborda el mismo asunto en carta que dirige al padre Juan Antonio Velázquez, provincial de Castilla en la Compañía de Jesús, se continúa presentando León como futuro retiro de la princesa ${ }^{116}$. En estas cartas Quevedo pone en duda la lealtad del príncipe Tomás y estos

112. Cartas de algunos pp. de la Compañía de Jesús, t. XIII, p. 407. Sobre la llegada de la princesa de Carignan, sus actividades, huidas y marcha de España, léanse Pellicer, Avisos, pp. $9,58,85,89,117,127,191-192,201,246,264,267,291,294,304,328-329,330,332$, $335,374,403,412,500,503,504,506,519,520,522$; Cartas de algunos pp. de la Compañía de Jesús, t. xIv, p. 24; XVI, pp. 233 y 239; xVII, pp. 97-98, y xIx, pp. 343; Jerónimo Gascón, Gaceta, pp. 397, 398, 400-403 y 411; Quevedo, Cartas, pp. 266, 269, 273; Quevedo, Nuevas cartas, pp. 86, 93-94, 112-113 y 141, y la relación sobre su entrada de Sánchez de Espejo, Relación ajustada (hay dos ejemplares en la BNE: R. 31479 y R. 11693 / 44).

113. Se le permitió salir de España a cambio de que a don Juan de Austria se le diese pasaporte para cruzar Francia hacia Flandes.

114. Pellicer, Avisos, pp. 328-329. Por otros avisos de Pellicer (pp. 374 y 403) sabemos que el 27 de mayo se encontraba aún en Carabanchel, y que a comienzos de septiembre -el día 9 fecha el aviso Pellicer- llegó a Madrid el conde Flaminio, Virago de Vichi, primer mayordomo del príncipe Tomás, «a pedir la ida de la señora princesa de Cariñán».

115. Quevedo, Nuevas cartas, pp. 93-94: «que a la de Cariñán la retiran a Las Huelgas de Burgos. Si esto no obliga a Tomás, según la aborrece, no hay que esperar a reducirle, aunque es tan fácil de tornillo». Tornillo: «fuga que hace el soldado de su regimiento» (Aut).

116. Quevedo, Nuevas cartas, pp. 112-113: “Hoy me ha dicho don Diego de Celis traen a esta ciudad [León] presa a la princesa de Cariñán, dejando en guarda a sus hijos en Madrid; dúdolo por no haber aquí convento ni parte donde pueda estar. Si viene a la ciudad, se poblará de presos y será cárcel real. De verdad no hay cosa que merezca por su marido, y no debe de haber cosa que él aborrezca más que a ella y a sus hijos». Diego de Celis, caballero de Santiago, en el año de 1635 era procurador en Cortes (Quevedo, Nuevas cartas, p. 259). 
recelos y desconfianza que Tomás de Saboya genera en Quevedo se perciben aun con mayor claridad en la fechada el 11 de septiembre ${ }^{117}$, y llega hasta el punto de considerarle capaz de sacrificar a su esposa e hijos. Unos meses antes, el 27 de agosto, ya había expuesto los mismos temores, pero en aquella ocasión llega a justificar el posible abandono de la princesa, por ser ella una malvada:

El tornillo a Francia de Tomás y su hermano hoy se dice y siempre se temió; yo no la tengo por novedad, que desde el año de 13 que le vi en Niza con su padre le dediqué el oxte, que se anda tras el puto en las hablillas. Este género de pegadizos suelen disimular hasta que pueden con una gran maldad granjear sus comodidades; si esto le ha sucedido, lo creo; si no, lo dudo, y no hago caso de que tiene en España sus hijos y su mujer, pues dicen que es de condición tan venenosa que es menester tomar triaca para hablarla. Ya se ve cuanta carga ha sido a sus majestades y a sus ministros ${ }^{118}$.

La descripción de la princesa de Carignan que nos interesa se incluye en la primera noticia sobre su traslado que comunica Quevedo, el 11 de septiembre de 1642, al padre Pimentel:

Después del desgarro militar de la princesa de Cariñán, hay aquí cartas de este ordinario, que la traen a León. Tendrá este infierno habitación de paraíso con Adán y Eva y la serpiente, que uno y otro temo ha de ser esta señora y acabar con el género humano; que siempre las ruinas grandes han sido especial hipoteca del ingenio de las mujeres ${ }^{119}$.

En esta ocasión el retrato de la princesa se bosqueja a partir de la escena que describe: un infierno - el convento-prisión de San Marcos de León-, en el que tendrá habitación de paraíso, porque allí se reunirán “Adán y Eva y la serpiente» ${ }^{120}$. La princesa, por su condición de mujer, tiene capacidad para dar fin a la humanidad o provocar grandes ruinas cuando todo queda fiado a sus malas artes; puesto que Eva es inductora del pecado, causante de los males que aquejan al hombre y responsable

117. Quevedo, Nuevas cartas, pp. 85-86 y 222-223.

118. Quevedo, Nuevas cartas, p. 81; los recelos de Quevedo hacia la casa de Saboya vienen de antaño y fueron extensamente expuestos en Lince de Italia, pp. 76 y ss., en la p. 83 leemos: «Mucho sentiría, señor, que el príncipe Tomás, que hasta ahora ha tenido por gala por defensa el traje francés y el ademán, hubiese vestídose a la española»; también véase Quevedo, La hora de todos, pp. 346.

119. Carta dirigida a Pedro Pimentel, el 11 de septiembre de 1642 (Quevedo, Nuevas cartas, p. 86, véanse también las pp. 215 y 223). Hipoteca: la prenda o alhaja que queda afecta y obligada a la seguridad y saneamiento de una compra, deuda, carga o venta, la cual se impone sobre los bienes inmuebles; también irónicamente vale cosa despreciable y en que se puede fiar poco (Aut); ingenio: facultad del hombre con que sutilmente inventa trazas, modos, máquinas, artificios, etc., y las mañas, trazas o artes que se usan para conseguir alguna cosa (Aut).

120. Se refiere a don Juan Adán de la Parra, inquisidor ordinario en la Corte. Encarcelado en San Marcos de León. Fue liberado, como Quevedo, tras la caída del conde duque de Olivares. Sobre los motivos de su prisión, léase Elliot, 1972. 
de la expulsión del Paraíso. En definitiva, Quevedo asigna a la princesa de Carignan todos los rasgos negativos de Eva ${ }^{121}$. La de Carignan, por ello, es uno y otro (infierno y paraíso) y puede suponer un serio peligro para la monarquía hispana.

El rey Felipe IV acogió en su Corte a la mujer e hijos de Tomás de Saboya y con ellos creía garantizarse la lealtad del príncipe. Si atendemos a las noticias que remite Quevedo a Sancho de Sandoval, para el año 1636, se recela en la corte de la lealtad del príncipe, recelos que él comparte:

Ahora titubean en el crédito de Tomás, y por lo menos dicen que él los metió en esta entrada enseñando firmas de grandes señores de Francia, con que ofrecían que en entrando él y el señor infante, se levantarían; faltaron todos, o lo que es más cierto, lo hicieron para faltar. Señor don Sancho, quien pelea con armas auxiliares es como el que anda con muletas, que le suplen mal los pies a costa de sus brazos y sus manos, que se mueven si las mueven, que ni pueden alcanzar ni retirarse, y siempre el que las lleva es tullido y ellas nunca son pies. La idea de una posible traición por parte del saboyano obligó, tras varios intentos de huida, a retenerla con sus hijos contra su voluntad, y vigilarla y guardarla por soldados para evitar que saliese de España ${ }^{122}$.

En los Avisos de Pellicer y en las cartas de los jesuitas se la describe como a una mujer celosa y envidiosa, testaruda e indómita, fama que unida a los problemas que causó por querer salir de España y sus posibles conspiraciones con La Mothe ${ }^{123}$ son razones suficientes para justificar el temor que manifiestan las palabras finales de Quevedo; recuérdese que en otra carta escribió sobre ella: «es de condición tan venenosa

121. Para la figura de Eva en la obra de Quevedo véase, Vallejo González, 2012, especialmente pp. 124-130.

122. Quevedo, Cartas, pp. 273-274, y 159-160; léanse Nuevas cartas, pp. 81, 85-86, 113. A finales de enero de 1642, cuando huye de la Corte, la dan alcance en Carabanchel. La noticia la da así Pellicer, Avisos, p. 332: «La señora princesa de Cariñano se está en Caramanchel de Abajo, sin haber querido volver a Madrid. Tiene de guarda 20 soldados de las de su majestad, ocho de la española, ocho de la tudesca y cuatro archeros que se remudan de cuatro a cuatro días». En una carta fechada el 26 de mayo de 1643 coleccionada en Cartas de algunos pp. de la Compañía de Jesús, XvII, pp. 97-98, también se hace referencia a la necesidad de tenerla custodiada cuando se descubre que se carteaba con La Mothe, con quien conspiraba y preparaba su huida: «En el último correo avisé a v. R. como don Francisco Antonio de Alarcón y José González, dos alcaldes de corte y 6 alguaciles y 24 de la guardia, habían ido a Carabanchel, donde asiste la princesa de Cariñano. No se sabía entonces la causa; luego se supo, y fue porque dicha señora se correspondía con mosieur de la Mota, y le tenía avisado que estuviese con 1.000 caballos en cierto puesto, y que ella se huiría con sus hijos y gente, y saldría de esta suerte de España [...]. Dijéronle como tenían orden de s. M. de llevarla a otra parte, y respondió que no se cansasen, que no saldría de allí si no era haciéndola pedazos [...]. Acordaron [...] dejarla con los alcaldes y alguaciles de guarda y con algunos soldados».

123. La Mothe fue un brillante militar francés, en 1642 Luis xiII le nombró mariscal de Francia, Virrey de Cataluña y duc de Cardone (Crosby, 2009, vol. 1, pp. 281-282). 
que es menester tomar triaca ${ }^{124}$ para hablarla». Teme que la de Carignan confirme las palabras del Rómulo: «Son las mujeres instrumentos de hacer perder reinos» ${ }^{125}$.

Sin embargo, no todos los retratos que hallamos en la correspondencia de Quevedo se integran en un contexto espacial o espacio temporal, como sucede con los siguientes seleccionados. Los primeros se insertan en una carta dirigida a Florencio de Vera y Chacón ${ }^{126}$, el 17 de marzo de 1637, desde Madrid. Se trata de una carta de nuevas, y en dos de ellas hallamos sendos retratos, uno de Virgilio Malvezzi ${ }^{127}$ y otro de Jerónimo Antonio de Medinilla y Porres.

Quevedo escribe a Florencio de Vera que le enviará una carta con un retrato de Malvezzi. Durante su estancia en Madrid, Quevedo recaba, entre otras noticias, una que hace referencia al marqués Virgilio Malvezzi, por tanto, el objetivo de este fragmento es comunicar a su corresponsal que el boloñés ha sido elegido para escribir una historia de Felipe IV y otra nueva del conde duque de Olivares ${ }^{128}$. Sin embargo, parece interesarle más describir las ocupaciones del historiador -entre las que no se halla la de escribir-y su físico, éste clara consecuencia de sus acciones:

El marqués Virgilio Malvezzi está encargado de escribir la historia de su majestad -Dios le guarde- y otra vez la de su excelencia. Por ahora su ocupación es pedir de comer y curarse, que yo río con él mucho, porque no bebe agua, que dice que le mata, ni vino, porque le destruye, ni carne porque no la puede digerir, ni pan porque no le puede morder. Y está tan flaco que parece esqueleto de cohete $^{129} \mathrm{y}$ admirándose de que yo como y bebo y tomo tabaco y chocolate ${ }^{130}$.

124. Triaca: medicamento compuesto de otros simples, la mayoría venenosos, que remedia a los que están emponzoñados con cualquier género de veneno (Cov.).

125. Quevedo, El Rómulo, p. 49.

126. Florencio de Vera y Chacón, caballero del hábito de Santiago, juez ordinario y vicario general perpetuo del campo de Montiel, vicario general de Villanueva de los Infantes, capellán de honor de Felipe IV, fue albacea testamentario de Quevedo y le asistió en los meses finales de su vida, según atestigua la correspondencia del escritor. Véase Tarsia, Vida, p. 144, y Crosby, 1997, pp. 118.

127. Quevedo fue el traductor de Il Romulo de Malvezzi. Véase Isasi, 1993a y 1993b, y muy especialmente Blanco, 2004.

128. Realmente el encargo consistía en componer una historia de España desde el reinado de Felipe III hasta el de Felipe IV. Sobre Malvezzi véase Brändli, 1964, y para su historia de Felipe IV véase Shaw, 1968. En 1635, Malvezzi había dado a la imprenta Il Ritratto del Privato Politico Christiano estratto dall'originale d'alcune attioni del Conte Duca di S. Lucar.

129. Cohete: «cañuto de papel reforzado con muchas vueltas, que tiene dentro la pólvora y un solo respiradero por donde prende el fuego y se abre como trueno» (Cov.). Estos cohetes o fuegos de artificio los había sin varilla, llamados buscapiés porque encendidos corren por la tierra entre los pies de la gente, o con una varilla por dentro (Diccionario histórico), aclara la confusión en 2011, p. 7, n. 16.

130. Quevedo, Cartas, p. 280. 
Como podemos leer, tras enumerar en oraciones bimembres lo que no come ni bebe y la razón de ello - «bebe / mata; vino / destruye; carne / no puede digerir; pan / no puede morder»-, acomete la prosopografía de Malvezzi, hechura del valido, con una oración comparativa: "está tan flaco, que parece esqueleto de cohete», donde se halla el chiste que arranca la carcajada final del lector. La semblanza dibujada por Quevedo debió acercarse mucho al físico del historiador, pues en las imágenes conservadas de Malvezzi se aprecia un rostro huesudo y afilado que apunta a que la delgadez era un rasgo definitorio de su aspecto $^{131}$. El carácter de Malvezzi es el resultado de ligar a la prosopografía la pragmatografía, pero además Quevedo le confiere un perfil burlesco con el que acerca esta representación del sujeto a una "figura» -hipocondríaco-, a lo que ha contribuido el símil establecido entre su físico extremadamente delgado y la varilla que lleva en su interior el cohete.

El otro retrato que encontramos en la carta dirigida a Florencio de Vera es de un individuo muy difícil de identificar por un lector distinto del destinatario o ajeno al círculo de amistades de los corresponsales. Escribe Quevedo sobre el enigmático sujeto: «Pondera v. м. extremadamente encontrarse con la inquisición fiado en el maldito Nicolás y preciarse de nicolaíta» ${ }^{132}$.

La identidad de este «nicolaíta» habría quedado oculta si no hubiese sido por una anotación de Sancho de Sandoval que se halla al margen de este fragmento en la carta autógrafa: «Todo esto es por don Jerónimo de Medinilla, que comenzaba a la sazón a ser corregidor de Córdoba, y nicolaíta lo dice por discípulo de Nicolás Machiaveli» ${ }^{133}$. Con el término «nicolaíta» a la vez que lo hace discípulo de Maquiavelo también lo asocia con la secta herética de los nicolaítas. El nombre completo es Jerónimo Antonio de Medinilla y Porres y, amén de existir entre ambos intereses intelectuales comunes ${ }^{134}$, debió pertenecer al círculo de per-

131. Puede verse un retrato suyo en el Archivo Storico de Italia (http://www.archiviostorico.unibo.it/it/?LN=IT).

132. Quevedo, Cartas, pp. 278-279. «Nicolaíta»: en plural, denominación de los seguidores de un tal Nicolás, de quien no se sabe nada y en quien se piensa en Apocalipsis, $2,6.15$. Es posible que la autodenominación de la secta pretendía relacionarse con el famoso helenista Nicolás, sin que realmente hubiera sido fundada por él (Balz y Schneider, Diccionario exegético, vol. 2, col. 409). Otros hacen cabeza de la secta a Nicolás, prosélito de Antioquía (Armesto y Goyanes, Diccionario histórico, pp. 218-219). Esta secta fue reprobada por compatibilizar la vida cristiana con el culto a los dioses (Sagrada Biblia. Nuevo Testamento, p. 1529); eran los nicolaítas «herejes de tipo gnóstico, al parecer, laxos en moral: enseñaban el libertinaje y la participación en sacrificios idolátricos) (Sagrada Biblia, p. 1426).

133. Quevedo, Cartas, p. 279, n. 343. En esta carta de Quevedo, Florencio de Vera escribe otra a don Sancho de Sandoval (en el reverso de la última hoja, fol. 39v), de esta forma llega la de Quevedo a las manos del de Beas. Véase reproducción digital en BNE, ms. 21883, fols. $38 \mathrm{r}-39 \mathrm{v}$.

134. Tanto Quevedo como Medinilla coincidieron en su interés por Tomás Moro, al que uno y otro leyeron con dedicación, como prueba el ejemplar de la Utopía que se conserva anotado por Quevedo (BNE, R / 20494) y la traducción realizada por Medinilla. 
sonas con las que el satírico madrileño tuvo alguna relación desde su señorío de la Torre de Juan Abad, esto queda patente por las reiteradas ocasiones en que aparece su nombre en la correspondencia que mantuvo con Sancho de Sandoval.

En este mismo año sale de la imprenta de Salvador de Cea, en Córdoba, la traducción de la Utopía de Tomás Moro realizada por Medinilla, con una «Noticia, juicio y recomendación» (pp. X-XII) escrita por Francisco de Quevedo. Por este texto preliminar a la obra de Moro, sabemos que fue Quevedo quien incitó a Medinilla a romancear la Utopía:

Este libro es corto, mas para atenderle como merece, ninguna vida será larga, escribió poco, y dijo mucho: si los que gobiernan le obedecen, y los que obedecen se gobiernan por él, ni [a] aquellos será carga, ni a estos cuidado. Por esto viendo yo a don Jerónimo Antonio de Medinilla y Porres que le llevaba por compañía en los caminos, y le tenía por tarea en las pocas horas que le dejaba descansar la obligación de su gobierno de Montiel le importuné a que hiciese esta traducción; asegurándome el acierto della, lo cuidadoso de su estilo y sin afectación; y las noticias políticas que con larga lección ha adquirido, ejecutándolas en cuanto del servicio de su majestad se le ha ordenado, y con gran providencia, y desinterés en el gobierno que tuvo destos partidos ${ }^{135}$.

Es posible que esa alusión a Medinilla, en los términos que hemos leído, esté relacionada con la traducción de la obra de Tomás Moro, lo que daría también sentido al inicio de la carta, inmediatamente anterior al fragmento analizado:

El Bochalino en un raguallo dice que viendo Apolo tan advertido y sentencioso a Cornelio Tácito, le dio una isla que gobernase, y que el tal Cornelio Tácito hizo en dos meses tan grandes disparates y locuras que le quitaron el cargo con gran vituperio suyo. Si al maestro aconteció tan gran desaire, amenaza es para los discípulos, y el Bocalino, a mi ver, se acordó del refrán «a ti te lo digo, Tácito; óyelo tú, Fulano» ${ }^{136}$.

Como sucede con este retrato, encontramos otros en el epistolario dibujados para sus corresponsales en los que la identificación del sujeto descrito no es fácil para un lector ajeno. Así sucede en la ya mencionada carta al marqués de Velada; allí escribe sobre un tal Mendoza: «Al estribo, Mendoza, el negro en duda y mulato de contado ${ }^{137}$. Afortunadamente en esta ocasión, para la identificación del personaje contamos con la respuesta del marqués a Quevedo, donde dice: “Andrés, aquel ano-

135. Tomás Moro, Utopía, pp. XI-XII.

136. Quevedo, Cartas, pp. 278, 279 notas 342 y 343 y pp. 166-169. Curiosamente, también en esa «Noticia...» preliminar de Quevedo a la traducción de Medinilla se menciona a Boccalini para acusarle de saquear la Utopía: «Hurtos son de cláusulas de la Utopía los más repúblicos raguallos del Bocalino, precioso caudal es, él que obligó, a que fuese ladrón a tan grande autor» (Tomás Moro, Utopía, p. xI).

137. Quevedo, Prosa festiva, p. 385. 
checido de rostro, tan Mendoza por línea curva como mulato por línea recta, ha enviado aquí quejas de que vuesa merced escribe las nuevas sin su licencia» ${ }^{138}$. Este Mendoza hemos de identificarlo con Andrés Almansa y Mendoza ${ }^{139}$. A tenor del retrato quevediano corroborado por Velada también podemos suponer que el relacionero, apologista de Góngora, era mulato o lo parecía.

Llegamos al final de esta colección antológica de retratos y figuras quevedianos con la mención de otros construidos con el recurso a la aposición, frecuente en Quevedo y en otros muchos autores del Siglo de Oro, con el que se crearon tantos neologismos. Fue en este periodo muy significativo el empleo de aposiciones equivalentes a símiles o metáforas concentrados $^{140}$. Quevedo empleó este recurso en su correspondencia para enviar a Sancho de Sandoval un brevísimo retrato de un «cura enfermedad» ${ }^{141}$, llamado en líneas anteriores «Fierabrás». El neologismo se forma con los antónimos cura y enfermedad, aprovechando Quevedo el valor trisémico del término cura: sacerdote; asistencia que se hace a un enfermo, aplicándole las medicinas para que sane, y la medicina que se aplica exteriormente para sanar heridas, llagas, etc. (Aut). El retrato se inició cuando Quevedo le bautizó con el sobrenombre de Fierabrás, protagonista de un cantar de gesta francés a quien se le atribuye el saqueo de Roma y el robo de dos barriles del bálsamo que se empleó para embalsamar el cuerpo de Cristo. Por último, Fierabrás es nombre de origen francés construido a partir de fier-à-bras, nombre digno de un bravucón. $\mathrm{Al}$ emplear este nombre Quevedo para referirse al sacerdote, aúna todas las posibilidades semánticas del neologismo, y todo ello explica claramente la enumeración de las acciones realizadas por él en la Torre:

Aquí envió el consejo por cura a Fierabrás, porque las cosas que en esta villa han sucedido con él no son creíbles: lo más honesto es ser amancebado público, con todo el escándalo y aparato de rufián, cuchilladas, resistencias y pistoletazos, encubridor de ladrones y de hurtos, inducidor de testigos falsos y otras tales curiosidades [...], esto está tan revuelto que me obliga a partir a toda prisa mañana a Madrid, al remedio [...]. Todo lo prometo para la vuelta, que habré convalecido deste cura enfermedad a esta pobre villa, que está afligida ${ }^{142}$.

138. Quevedo, Epistolario, p. 121.

139. Ettinghausen, 1994, p. 37. Sobre la identidad de Almansa y Mendoza léase Ettinghausen y Borrego, 2001, pp. 15-24.

140. Esto lo explicó ya Lapesa, 1980, p. 336, aduciendo ejemplos extraídos de obras de Quevedo - (galanes moscateles», «poetas chirles y hebenes»-, Lope -«trujeron toros leones / para Hércules caballeros»-, Tirso - «conocimientos linces», (voces sirenas».

141. Quevedo, Prosa festiva, p. 463.

142. Quevedo, Cartas, pp. 241 y 245. «Remedio», “convalecido», (afligida» «cura»y «enfermedad» son todos cinco términos que pertenecen al campo semántico de la medicina y se relacionan con los conceptos de sanación o dolencia. 
En primer lugar Quevedo ha realizado la descripción del cura bravucón y pendenciero y finalmente le asigna un término de nuevo cuño que corresponde a un tipo de sacerdote también nuevo. De igual manera procede en la Carta de las calidades de un casamiento, cuando describe a su mujer ideal y habla de la «mujer pesadumbre»; aquí también antes de emplear el neologismo explica su significado ${ }^{143}$ :

De alegre o triste, más la quiero alegre; que en lo cotidiano y en lo propio no nos faltará tristeza a los dos, y eso templa la condición suave y regocijada con ocasión decente: porque tener una mujer-pesadumbre, más arrinconadas que telaraña, influyendo acelgas, es juntarme un pésame de por vida ${ }^{144}$.

Destacamos un ejemplo más - «tarascas mosqueteros»- inserto en una carta en la que la descripción se centra en la persona de un emir:

no he acabado de maldecir al emir. Pues si no fuera por él, bien sé yo que el gato hubiera cazado. Considérole yo con su cara de albondiguilla barbada, muy estevadico, cercado de tarascas mosqueteros, maullando por las marinas [...]. Pero el emir es un puto y le tengo más maldito que a un casamentero $^{145}[\ldots]$. Nunca tuve buen conceto de aquel emir desde que dio a V. Ex ${ }^{\mathrm{a}}$ aquel cuchillo encantado ${ }^{146}$.

Quevedo escribe a Osuna desde Madrid, el 13 de abril de 1616, con el único fin de darle cuenta de lo tratado con Rodrigo Calderón sobre

143. Emplea el mismo procedimiento para describir al licenciado Cabra del Buscón, llamado “clérigo cerbatana», sin embargo en esta ocasión el orden es inverso, al sintagma le sigue la detallada descripción del licenciado que se ajusta perfectamente al neologismo: «Él era un clérigo cerbatana, largo sólo en el talle; [...] los brazos, secos; las manos, como un manojo de sarmientos cada una; mirado de medio abajo, parecía tenedor u compás, con dos piernas largas y flacas» (Quevedo, La vida del Buscón, p. 67).

144. Quevedo, Prosa festiva, p. 463.

145. Estevadico: Se llama estevado al que tiene las piernas en arco (Aut); sobre el uso del diminutivo véanse Latorre, 1956-1957, pp. 113-114, y Amado, 1982, p. 167, n. 7. Tarascas mosqueteros: La tarasca es una sierpe contrahecha que suelen sacar en algunas fiestas con regocijo. Díjose así porque espanta a los muchachos (Cov.); sale delante de la procesión del Corpus y representa místicamente el vencimiento de Jesucristo del monstruoso Leviatán (Aut); la hacían andar unos 8 o 10 hombres que iban en su interior, véase Quevedo, La hora de todos..., p. 116-117, n. 175. Mosquetero: el mosquetero es el soldado que lleva mosquete $(A u t)$. Con maullar se hace referencia a gato, ladrón ratero que hurta con astucia y engaño. Maldito: aquel a quien han echado maldiciones; también significa perverso, malvado, de mala intención y dañadas costumbres (Aut). Marina: parte de tierra inmediata al mar (Aut). Maldito [...] casamentero: Astrana Marín anota "siempre tuvo don Francisco extraña ojeriza a los casamenteros», afirmación que apoya con una cita del Sueño de la muerte, p. 334: «¿Maldiciones queréis que falten donde hay casamenteros y sastres, que son la gente más maldita del mundo?»; no es esta la única ocasión en la que Quevedo tilda a los casamenteros de malditos, también lo hizo en la Hora de todos, p. 113 y en el Discurso de todos los diablos, 1988, p. 236 (citamos por esta edición, por haberse suprimido este fragmento en el texto editado en 2005). Sobre el «casamentero» en la obra de Quevedo véase Mas, 1957, pp. 93-95.

146. Carta dirigida al duque de Osuna, fechada en Madrid, el 13 de abril de 1616 (Quevedo, Epistolario, p. 38). Véase Ettinghausen, 2011, pp. 11-12. 
los servicios prestados a su majestad por el emir de Saida ${ }^{147}$. Tras ello, con la libertad que ofrece la comunicación epistolar, enjuicia a dicho emir, y lo hace a través de un retrato deformante, que lo representa como una bola de carne con barba y dos piernas arqueadas, rodeado de hombres armados que amedrentan y causan temor. Quevedo desconfía del emir, por ello afirma que es «un puto y le tengo más maldito que a un casamenterom, pues estos engañan y mienten para conseguir su beneficio, como la figura quevediana, también tildada de maldita, del Discurso de todos los diablos:

-Pues no soy -dijo el tal figura- sino casamentero. Soy sastre de hombres y mujeres que zurzo y junto, y miento en todo y hurto la mitad. Yo soy embelecador de por vida, inducidor de divorcios [...].

-¿Hay ladrón como este? -dijo el Soplón ${ }^{148}$.

La inserción de estas descripciones, construidas por este procedimiento de la aposición, en el que un sustantivo califica a otro sustantivo, como bien explicó Lapesa ${ }^{149}$, “acusan vivacidad mental, rápida asociación de ideas, y que requieren también despierta comprensión en el lector u oyente», como sucede con otras igual de breves trazadas en sintagmas nominales o adjetivales, en escuetas frases descriptivas yuxtapuestas en relación de paralelismo o de antítesis, por analogía, etc., todos frecuentes recursos empleados por Quevedo en sus obras literarias y de los que se han visto algunos casos en sus cartas. Los ejemplos de retratos y figuras, coleccionados de la correspondencia, toman de modelos a sujetos de carne y hueso de los que Quevedo ha sabido captar la esencia para transformarlos en literatura. Así pues, con estas muestras recogidas de la realidad, podemos reafirmarnos en las certeras palabras de Emilio Orozco sobre lo visual y lo pictórico en la obra del escritor:

147. En el año 1614 el emir de Saida colaboró con los duques Cosme de Medici y de Osuna en sus campañas contra el turco (Fernández Duro, 2006, pp. 84-86); a la colaboración del emir y a su protección alude Osuna en una carta dirigida a Felipe III, fechada en Palermo el 5 de febrero de 1614. De nuevo, en carta escrita a su majestad, en Trápana, el 30 de abril de 1616 -7 días después de la carta de Quevedo-, Osuna hace referencia a un emir, que no puede ser otro que al que alude Quevedo. Escribe Osuna: «El capitán Pedro Sánchez volvió con el emir, y lo que sucintamente he sacado en limpio, es que el gobierno de todas aquellas tierras le tiene su hijo; que el dicho emir es allá deseado, y que siempre que v. м. fuere servido de ir con armada a sus puertos, los entregará; y lo que de v. м. pide es una cédula para él y sus sucesores, que ganándose aquella tierra y la casa santa de Jerusalén, v. м. le dejará en libre posesión de la tierra firme que hoy tiene, ayudando él en todo al real servicio de v. M.» (Colección de documentos inéditos, XLv, pp. 13-18 y 387388). Osuna escribe otra vez a su majestad -Nápoles, 18 de junio de 1619- una carta a la que adjunta otra del marqués de Bedmar dirigida al duque, para tratar de nuevo de la situación (servicios prestados a la monarquía, seguridad y regreso a su casa) del emir de Saida (Colección de documentos inéditos, XLVII, pp. 162-163).

148. Quevedo, Discurso de todos los diablos, 1988, p. 236.

149. Lapesa, 1980 , p. 335. 
A Quevedo la materia esencial de la creación artística se le ofrecía como la misma realidad: como pura ficción de visiones y palabras; algo inconsistente que se deshace y pasa como figura y versos de personaje teatral. En la carta, tantas veces citada, del escritor dirigida en sus últimos días a su amigo don Francisco de Oviedo -donde condensa su dolorido sentimiento de desengaño del mundo, ante las malas nuevas que recibía de todas partes- declara rotundamente cómo todo el mundo se reduce a pura apariencia: «Esto señor don Francisco no sé si se va acabando ni si se acabó, Dios lo sabe; que hay muchas cosas que pareciendo que existen y tienen ser, ya no son nada, sino un vocablo y una figura» ${ }^{150}$.

En los casos en los que se incluyen extensas descripciones de personas, observamos que estas colaboran notablemente a difuminar la débil línea que separa la carta, entendida como canal de comunicación, de un texto resultante de las prácticas literarias, donde el destinatario deja de ser el lector real ${ }^{151}$ - cartas dirigidas al marqués de Velada y a la condesa de Olivares-, o donde el retrato se inserta en un contexto espacio temporal concreto, entonces aquel se aproxima a la caracterización de un personaje ficcional a la vez que se distancia de la descripción de un individuo real -carta dirigida al duque de Medinaceli, 21 de diciembre de 1630-. Pero sin duda, en todas las cartas en las que Quevedo decide introducir la descripción de un sujeto, por breve que sea, la misiva gana en interés para el destinatario y también para el lector actual, por suponer siempre una extraordinaria y sorprendente muestra del ingenio quevediano.

\section{Bibliografía}

Alarcos García, Emilio, «Quevedo y la parodia idiomática», Archivum, v, 1, 1955 , pp. 3-38.

Aldea Vaquero, Quintín, España y Europa en el siglo XVII. Correspondencia de Saavedra Fajardo. El cardenal infante en el imposible camino de Flandes (16331634), Madrid, csic / Real Academia de la Historia, 2008, t. III, vol. I.

Amado, Alonso, “Noción, emoción, acción y fantasía en los diminutivos», en Estudios lingüísticos. Temas españoles, Madrid, Gredos, 1982, pp. 161-189.

Arellano Ayuso, Ignacio, “Primera parte», en Francisco de Quevedo, Poesía satírico burlesca, Pamplona / Madrid / Frankfurt am Main, Universidad de Navarra / Madrid / Iberoamericana, 2003, pp. 15-345.

Arranz Lago, David, «La afirmación identitaria de Quevedo y el discurso social del siglo XviI», Dicenda. Cuadernos de Filología Hispánica, 27, 2009, pp. 5-18.

Azaustre Galiana, Antonio, Paralelismo y sintaxis del estilo en la prosa de Quevedo, Santiago de Compostela, Universidade, 1996.

Balz, Horst y Gerhard Schneider, Diccionario exegético del «Nuevo Testamento», Salamanca, Sígueme, 1996-1998, 2 vols.

150. Orozco, 1982, p. 419. El texto de Quevedo pertenece a una carta que dirige a don Francisco de Oviedo, desde Villanueva de los Infantes, a 21 de agosto de 1645 (Quevedo, Nuevas cartas, p. 188).

151. Guillén, 1998, pp. 187-190, distingue entre el destinatario que aparece en la carta y el lector real, considera destinatario al «tú» que el «yo» empírico tiene presente al escribir. 
Blanco, Mercedes, «Quevedo lector de Malvezzi», La Perinola, 8, 2004, pp. 77108.

Beltrán Almería, Luis, «Las estéticas de los géneros epistolares», 1616. Anuario de la Sociedad Española de Literatura General y Comparada, 10, 1996, pp. 239-246.

Beltrán Almería, Luis, «La carta, una aproximación teórica», en Cristina Balletín y Luisa Paz Rodríguez Suárez, Discursos subterráneos. Pensamiento y epistolaridad, Zaragoza, Mira Editores, 2009, pp. 75-83.

Borrego, Esther, «Portugal y los portugueses en el teatro cómico breve del siglo XVII: de los entremeses a los villancicos», Hipogrifo, 3, 2, 2015, pp. 49-69.

Bouza Álvarez, Fernando, "Cartas secas y cartas nuevas. "Lo que hay de nuevo que avisar es" », en Corre manuscrito. Una historia cultural del Siglo de Oro, Madrid, Marcial Pons, 2001, pp. 137-177.

Brändli, Rodolfo, Virgilio Malvezzi: Politico e moralista, Basilea, Tipografia dell'usc, 1964.

Cabo Aseguinolaza, Fernando y Santiago Fernández Mosquera, «Introducción», en Francisco de Quevedo, Execración contra los judíos, Barcelona, Crítica, 1993, pp. 9-76.

Cartas de algunos pp. de la Compañía de Jesús sobre los sucesos de la monarquía entre los años de 1634 y 1648, en Memorial histórico español. Colección de documentos, opúsculos y antigüedades, Madrid, Imprenta Nacional, 1862-1863, vols. XIII-XVII.

Castillo Gómez, Antonio, «Del tratado a la práctica. La escritura epistolar en los siglos XVI y XVII», en Actas del vI Congreso Internacional de historia de la cultura escrita. La correspondencia en la historia. Modelos y prácticas de la escritura epistolar, eds. Carlos Sáez Sánchez y Antonio Castillo Gómez, Alcalá de Henares, Calambur, 2002, vol. 1, pp. 79-107.

Colección de documentos inéditos para la historia de España, por el marqués de Pidal y Miraflores y Miguel Salvá, Madrid, Imprenta de la viuda de Calero, 1864 y 1865 , vols. XLV y XLVII.

Crosby, James O., "Quevedo y la milicia sagrada: "Dejar la compañía propia por la de Jesús"», en Silva Studia Philologica in Honorem Isaías Lerner, coords. Isabel Lozano Renieblas y Juan Carlos Mercado, Madrid, Castalia, 2001, pp. 181-197.

Crosby, James O., Indice onomástico, toponímico y bibliográfico de las cartas de jesuitas, 1634-1648, Woodbridge, Tamesis, 2009, 2 vols.

Diccionario histórico, Madrid, Hernando, 1933-1936, 2 vols.

Elliot, John H., "Nueva luz sobre la prisión de Quevedo y Adán de la Parra», Boletín de la Real Academia Española, CLXIX, 1972, pp. 171-182.

Ettinghausen, Henry, "Quevedo y las actualidades de su tiempo», Edad de Oro, XIII, 1994, pp. 31-46.

Ettinghausen, Henry y Manuel Borrego, «Identidad del autor», en Andrés de Almansa y Mendoza, en Obra periodística, Madrid, Castalia, 2001, pp. 15-24.

Ettinghausen, Henry, «Relación y nuevas y visitas: la primera carta conservada al duque de Osuna», La Perinola, 10, 2006, pp. 73-86.

Ettinghausen, Henry, “El diablo anda suelo": sátira y burla en las cartas de Quevedo al duque de Osuna», en Estudios sobre Quevedo y la sátira en el siglo XVII, ed. Carlos Vaíllo y Ramón Valdés, Barcelona, PPU, 2011, pp. 1-22.

Ezquerra Revilla, Ignacio, «Jornadas reales, red viaria y espacio cortesano en tiempo de Felipe IV: las prevenciones camineras del doctor Juan de Quiñones, alcalde de Casa y Corte», Libros de la Corte, 3, 2011, pp. 36-51. 
Fundación casa ducal Medinaceli, La casa ducal, Sevilla, Fundación casa ducal de Medinaceli (http://www.fundacionmedinaceli.org/)

García Padrón, Dolores y José Juan Batista Rodríguez, “Compilación, desautomatización y desarticulación fraseológica en Quevedom, en Fraseología española: Diacronía y codificación, ed. M. ${ }^{a}$ Teresa Echenique Elizondo, M. ${ }^{a}$ José Martínez Alcalde, Juan Pedro Sánchez Méndez y Francisco P. Pla Colomer, Madrid, csic, 2016, pp. 111-131.

Gascón de Torquemada, Jerónimo, Gaceta y nuevas de la corte de España desde el año 1600 en adelante, continuado por Jerónimo Gascón de Tiedra, Madrid, Real Academia Matritense de Heráldica y Genealogía, 1991.

Gómez Moreno, Ángel, España y la Italia de los humanistas. Primeros ecos, Madrid, Gredos, 1994.

Góngora, Luis de, Antología poética, ed. Antonio Carreira, Barcelona, Austral, 2015.

Guillén, Claudio, "Notes Toward the Study of Renaissance Letter», en Renaissance genres. Essays on Theory, History and Interpretation, ed. Barbara Kiefer, Cambridge (Massachusetts) / London (England), Haward University Press, 1986, pp. 70-101.

Guillén, Claudio, “Al borde de la literariedad: literatura y epistolaridad», Tropelías, 2, 1991, pp. 71-87.

Guillén, Claudio, «La escritura feliz: literatura y epistolaridad», en Múltiples moradas. Ensayo de literatura comparada, Barcelona, Tusquets, 1998, pp. 177-233.

Hermès, Delphine, “Carta de don Francisco de Quevedo sobre casarse. Hacia unas capitulaciones matrimoniales entre una rendición de veras y una petición de burlas», en Cartas-Lettres-Lettere: Discursos, prácticas y representaciones epistolares (siglos $X I V-X X$ ), dir. Antonio Castillo Gómez y Verónica Sierra Blas, Alcalá de Henares, Universidad de Alcalá, 2014, pp. 551-563.

Iriarte López, Margarita, El retrato literario, Pamplona, Eunsa, 2004.

Isasi, Carmen, “Introducción», en Francisco de Quevedo, El Rómulo, ed. Carmen Isasi, Bilbao, Universidad de Deusto, 1993a.

Isasi, Carmen, "Quevedo itraductor negligente? Observaciones sobre el texto del Rómulom, Livius, 4, 1993b, pp. 89-96.

Jauralde Pou, Pablo, Francisco de Quevedo (1580-1645), Madrid, Castalia, 1998.

Julio, Teresa, "Vejamen de Alfonso de Batres para la Academia de 1638 (manuscrito inédito). Estudio y edición crítica», Revista de Literatura, 75, 149, 2013, pp. 279-306.

Lapesa, Rafael, Historia de la lengua española, pr. Ramón Menéndez Pidal, Madrid, Gredos, $1980^{8}$.

Latorre, Federico, «Diminutivos, despectivos y aumentativos en el siglo XVII», Archivo de Filología Aragonesa, viII-IX, 1956-1957, pp. 105-120.

Lida, Raimundo, "Quevedo en sus cartas», en Prosas de Quevedo, Barcelona, Crítica, 1980, pp. 15-40.

Madroñal, Abraham, «El Vejamen de Antonio Hurtado de Mendoza en Sevilla (1624) y su relación con una carta de Quevedom, La Perinola, 8, 2004, pp. 235-255

Martín Baños, Pedro, El arte epistolar en el Renacimiento europeo 1400-1600, Bilbao, Universidad de Deusto, 2005.

Martínez Bogo, Enrique, Retórica y agudeza en la prosa satírica-burlesca de Quevedo, Santiago de Compostela, Universidade, 2009 (http://hdl.handle. net/10347/2611). 
Martínez Hernández, Santiago, «Aristocracia y gobierno. Aproximación al cursus honorum del marqués de Velada, 1590-1666», en Francisco José Aranda Pérez, coord., VII ${ }^{a}$ Reunión científica de la Fundación Española de Historia Moderna. La declinación de la monarquía hispana, Ciudad Real, Universidad de Castilla-La Mancha, 2004a, vol. 1, pp. 155-168.

Martínez Hernández, Santiago, El marqués de Velada y la corte en los reinados de Felipe II y Felipe III: nobleza cortesana y cultura política en la España del Siglo de Oro, Valladolid, Junta de Castilla y León, 2004b.

Martínez Millán, José y $\mathrm{M}^{\mathrm{a}}$ Antonietta Visceglia, (dirs.), La monarquía de Felipe III: La casa del rey, Madrid, Fundación Maphre / Instituto de Cultura, 2008, vol. II.

Mas, Amédée, La caricature de la femme, du mariage et de l'amour dans l'oeuvre de Quevedo, Paris, Edit. Hispano-Americanas, 1957.

Mercado Egea, Joaquín, La muy ilustre villa de Santisteban del Puerto, Madrid, [Gala, A.G.], 1973.

Moreri, Louis, El gran diccionario histórico o Miscelánea curiosa de la historia sagrada y profana, Paris / Lyon, a consta de los Libreros privilegiados / Hermanos Detournes, 1753, t. viII.

Navarro Bonilla, Diego, Cartas entre espías e inteligencias secretas en el siglo de los validos: Juan de Torres-Gaspar Bonifaz, 1632-1638, [Madrid], Ministerio de Defensa, 2007.

Nider, Valentina, Una «consolatio» de Quevedo. La Carta a Antonio de Mendoza, Firenze, Alinea Editrice, 2013.

Orozco Díaz, Emilio, «Lo visual y lo pictórico en el arte de Quevedo. (Notas sueltas para una ponencia sobre el tema)», Homenaje a Quevedo. Academia Literaria Renacentista, II, Salamanca, Universidad de Salamanca, 1982, pp. 417-454.

Ortega y Sagrista, Rafael, «La visita de Felipe IV a Jaén», Boletín del Instituto de Estudios Giennenses, 98, 1978, pp. 55-90.

Pacheco de Narváez, Luis, El tribunal de la justa venganza, ed. Victoriano Roncero López, Pamplona, Eunsa, 2008.

Páez de Valenzuela y Castillejo, Juan, Para secretarios de señores y todo género [de personas], [Madrid], Imprenta del Reino, a costa de Antonio Ribero [Rodríguez], 1650.

Pellicer de Tovar, José, Avisos, ed. Jean-Claude Chevalier y Lucien Clare con nota al manuscrito de Jaime Moll, Paris, Editions Hispaniques, 2002, 2 vols.

Pérez Cuenca, Isabel, Catálogo de manuscritos de Quevedo en la Biblioteca Nacional, Madrid, Ollero \& Ramos, 1997.

Pérez Cuenca, Isabel, «Francisco de Quevedo y el VII duque de Medinaceli: cajón de sastre noticierom, en La corte de Barroco. Textos literarios, avisos, manuales de corte, etiqueta y oratoria, ed. Antonio Rey Hazas, Mariano de la Campa Gutiérrez y Esther Jiménez Pablo, Madrid, Polifemo, 2016, pp. 169-264.

Pérez Cuenca, Isabel y Mariano de la Campa Gutiérrez, «Algunas consideraciones sobre Quevedo y Olivares. Una revisión historiográfica), en $L a$ Corte de Felipe IV (1621-1665). Reconfiguración de la Monarquía católica. Espiritualidad, literatura y teatro, dir. José Martínez Millán y Manuel Rivero Rodríguez, Madrid, Polifemo, 2017, t. 3, vol. 3, pp. 1949-2012.

Plata, Fernando, "Risas de ida y vuelta: León y Arce con Quevedo de viaje a Andalucía», La Perinola, 20, 2016, pp. 157-202.

Pope-Hennessy, John, El retrato en el Renacimiento, Madrid, Akal, 1985. 
Quevedo, Francisco de, Carta de las calidades de un casamiento, ed. Delphin Hermès, Clásicos Hispánicos, 2014 (ebook).

Quevedo, Francisco de, Cartas a Sancho de Sandoval, ed. paleográfica y notas de M $^{\text {a }}$ Carmen Laiz Sasiain, Bilbao, Universidad de Deusto, 1974 (Memoria de Licenciatura dirigida por Luisa López Grigera). [http://uvadoc.uva.es/ handle/10324/7535]

Quevedo, Francisco de, Cartas a Sancho de Sandoval, ed. Mercedes Sánchez Sánchez, Madrid, Calambur, 2009.

Quevedo, Francisco de, Cartas, documentos y escrituras, ed. Krzysztof Sliwa, Pamplona, Eunsa, 2005.

Quevedo, Francisco de, Discurso de todos los diablos, en Obras completas. Prosa, ed. Felicidad Buendía, Madrid, Aguilar, 1988, vol. 1, pp. 220-253.

Quevedo, Francisco de, Discurso de todos los diablos, ed. Miguel Marañón, Madrid, Fundación Universitaria Española, 2005.

Quevedo, Francisco de, El Rómulo, ed. Carmen Isasi, Bilbao, Universidad de Deusto, 1993.

Quevedo, Francisco de, Epistolario completo, ed. Luis Astrana Marín, Madrid, Instituto Editorial Reus, 1946.

Quevedo, Francisco de, La hora de todos y la Fortuna con seso, ed. Lía Schwartz, Madrid, Castalia, 2009.

Quevedo, Francisco de, Lince de Italia u zahorí español, ed. Ignacio Pérez Ibáñez, Pamplona, Eunsa, 2002.

Quevedo, Francisco de, Nuevas cartas de la última prisión de Quevedo, ed. James O. Crosby, Woodbrige, Tamesis, 2005.

Quevedo, Francisco de, Obra poética, ed. José Manuel Blecua, Madrid, Castalia, 1969-1971, vols. I-III.

Quevedo, Francisco de, Obras, ed. Aureliano Fernández Guerra, Madrid, Atlas, 1951, vol. 2.

Quevedo, Francisco de, Obras burlescas, ed. Antonio Azaustre, en Obras completas en prosa, dir. Alfonso Rey, Madrid, Castalia, 2007, vol. II, t. I.

Quevedo, Francisco de, Prosa festiva completa, ed. Celsa Carmen García Valdés, Madrid, Cátedra, 1993.

Rivarola y Pineda, Juan Félix Francisco, Monarquía española. Blasón de nobleza. Parte segunda, Madrid, imprenta de Alfonso de Mora, 1736.

Sagrada Biblia, versión crítica sobre los textos hebreo, arameo y griego, por Francisco Cantera Burgos y Manuel Iglesias González, Madrid, Biblioteca de Autores Cristianos, 1979.

Sagrada Biblia. Nuevo Testamento, Pamplona, Eunsa, 2008.

Sánchez de Espejo, Andrés de, Relación ajustada en lo posible a la verdad y repartida en dos discursos. El primero, de la entrada en estos reinos de madama María de Borbón, princesa de Cariñán. El segundo, de las fiestas que se celebraron en el real palacio del Buen Retiro, a la elección del rey de romanos, Madrid, María de Quiñones, 1637.

Sánchez Sánchez, Mercedes, «Lo público y lo privado: acerca del epistolario de Francisco de Quevedom, Edad de Oro, 12, 1993, pp. 293-302.

Sánchez Sánchez, Mercedes, «Aspectos biográficos, literarios e históricos del epistolario de Quevedom, Edad de Oro, 13, 1994, pp. 161-170.

Sánchez Sánchez, Mercedes, «La Respuesta de Sancho de Sandoval a la Carta de Quevedo a la condesa de Olivares, obra festiva autógrafa y desconocida. Notas sobre el archivo de don Alonso Mesía de Leyva», en Studies in Honor 
of James $O$. Crosby, ed. Lía Schwartz, Newark (Delaware), Juan de la Cuesta, 2004, pp. 333-355.

Sandoval, Sancho de, Respuesta a la carta que D. Francisco de Quevedo escribió a la Condesa de Olivares, sobre si es mejor tener mujer fea que hermosa, Biblioteca Nacional de España (вNE), ms. 20274 / 3.

Schwartz, Lía, «Notas sobre el retrato literario en la obra satírica de Quevedo», Revista del Instituto [Nacional del Profesorado. Buenos Aires], I, 1974, pp. 122142.

Schwartz, Lía, Metáfora y sátira en la obra de Quevedo, Madrid, Taurus, 1984.

Schwartz, Lía, Quevedo, discurso y representación, Pamplona, Eunsa, 1986.

Shaw, Donald L., “Estudio preliminar», en Virgilio Malvezzi, Historia de los primeros años del reinado de Felipe IV, ed. Donald Shaw, London, Tamesis Books, 1968, pp. IX-LIV.

Tarsia, Paolo Antonio de, Vida de don Francisco de Quevedo, repr. facs. cuidada por Melquiades Prieto Santiago, pr. Felipe B. Pedraza Jiménez, Aranjuez [Madrid], Ara Iovis, 1988.

Tomás Moro, santo, Utopía, traducida del latín en castellano por don Jerónimo Antonio Medinilla y Porres, Córdoba, por Salvador de Cea, 1637.

Vallejo González, María, «Las figuras de Eva y María en la obra de Quevedo», La Perinola, 16, 2012, pp. 123-152. 